Article

\title{
An Integrated Approach for Modeling Ontology-Based Task Knowledge on an Incident Command System
}

\author{
Kwoting Fang * and Shuoche Lin \\ National Yunlin University of Science and Technology, Douliu City, Yunlin County 640, Taiwan; \\ diablo79802@gmail.com \\ * Correspondence: fangkt@yuntech.edu.tw
}

Received: 15 April 2019; Accepted: 18 June 2019; Published: 25 June 2019

check for updates

\begin{abstract}
This paper presents the TTIPP methodology, an integration of task analysis, task ontology, integration definition function modeling (IDEF0), Petri net, and Petri net mark language (PNML), to organize and model the task knowledge in the form of natural language expressions acquired during the knowledge-acquisition process. The goal of the methodology is to make the tasks more useful, accessible, and sharable through the web for a variety of stakeholders interested in solving a problem which is expressed mostly in linguistic form, and to shed light on the nature of problem-solving knowledge. This study provides a core epistemology for the knowledge engineer while developing the task ontology for a generic task. The proposed model overcomes the drawbacks of IDEF0, which are its static nature and Petri net which has no concept of hierarchy. A good number of countries lie on the typhoon and earthquake belts, which make them vulnerable to natural calamities. However, a practical incident command system (ICS) that provides a common framework to allow emergency responders of different backgrounds to work together effectively for standardized, on-the-scene, incident management has yet to be developed. There is a strong need to explicitly share, copy, and reuse the existing problem-solving knowledge in a complex ICS. As an example, the TTIPP model is applied to the task of emergency response for debris-flow during a typhoon as a part of an ICS.
\end{abstract}

Keywords: problem-solving; incident command system; task ontology; knowledge management

\section{Introduction}

In the past few decades, several large-scale earthquakes have occurred in various parts of the world, such as the 1994 Northridge earthquake in the U.S., the 1995 Hanshin-Awaji earthquake in Japan, the 1999 Chi-chi earthquake in Taiwan, and the 2001 Izmit earthquake in Istanbul, Turkey. In 2003, a series of earthquakes shook parts of the world, including Altay, Russia; Boumerdes, Algeria; Hokkaido, Japan; Bam, Iran. These were followed by the December 2004 earthquake in Indonesia, with its devastating large-scale tsunami. Recently, in 2019, an earthquake hit the Sulawest, Indonesia; off the East Coast of Honshu, Japan; South Sandwich Islands Region; and Banda Sea, respectively [1]. These natural calamities caused tragic loss of life, severe property damage, and a decline in regional prosperity.

Although a lot of effort has been spent on protecting people from natural calamities around the world, some countries which lie on the typhoon and earthquake belts, are still vulnerable to natural calamities. However, there is no practical incident command system (ICS) that provides a common framework allowing people to work together effectively for standardized, on-the-scene, incident management. There is a strong need to explicitly share, copy, and reuse prior or existing problem-solving knowledge in a complex ICS.

In general, there are four ICS stages: mitigation, preparedness, response, and post-disaster reconstruction, and each stage needs a complex and dynamic problem-solving method. ICS is a 
complex problem which requires collaboration and participation among many different stakeholders with conflicting interests and it also covers the complex aspects of environmental, economic, and social problems. With the vigorous development and rapid spread of the World Wide Web, a significant quantity of information is available to people. However, reusable and sharable problem-solving knowledge in an ICS has emerged much more slowly. A stream of existing knowledge representation techniques can be used, including semantic networks, frames, uncertain reasoning, ontology, and rules, etc. [2-6]. For a complex problem, such as an incident command system, simpler mechanisms, using declarative statements that are true or false, as semantic networks or frames are not appropriate. In a similar sense, uncertainty reasoning only provides solutions for situations when true or false conclusions cannot be reached, which may lead to conflicts with problem-solving knowledge in managerial practice [7].

To bridge the gap between real-world problem-solving methods and information found on the Internet and to enable people to communicate with computers by using accurate syntax and semantics, this research proposes a novel model not only for effectively capturing and representing real-world problem-solving knowledge, but also for overcoming the drawbacks of the existing methodologies for integration of heterogeneous information. The concept of task ontology is first adopted to build a three-level mediation representation for a task analysis. Second, an integrated methodology, integrating task analysis, task ontology, integration definition function modeling (IDEF0), Petri net, and Petri net mark language (PNML) (TTIPP), is proposed to systematically analyze the tasks and subtasks in terms of the inputs, outputs, mechanisms, and controls, using integration definition function modeling (IDEF0) and Petri net. Finally, Petri net mark language (PNML) is used as a standard interchange format to make the tasks of searching, displaying, integrating, and maintaining more assessable through the web. The practicality of the proposed model is demonstrated through an emergency response for debris-flow cases. It is hoped that this model lays the groundwork for understanding how to build reusable and sharable real-world problem-solving knowledge.

\section{Related Work}

\subsection{Knowledge Management}

With the dramatic growth of globalization and the necessity to boost value creation, knowledge has continuously played the important role of being the major source of sustainable advantage [8]. Alonderienne et al. [9] defined knowledge as being the result of a process which combines ideas, rules, procedures, and information. Specifically, based on reasoning and understanding, made by the mind, through the posterior and the frontal hierarchy of cognitive networks, people can capture perceptual information and executive information through experience, learning, or introspection [10]. From an evolutionary economic standpoint, Erkut [11] pointed out that the generation of new knowledge, in turn of shaping markets, is associated with the perception of objectively available information in a system (called the nano dimension). Perception means that an individual classifies a certain experience according to his or her own categorization by means of a pattern recognition, through the interactions of hierarchical networks in the cerebral cortex, based on similar past experiences existing in an ever-evolving cerebral cortex [12]. Polanyi [13] divided knowledge into two categories: tacit (weak) and explicit (hard) knowledge. Explicit knowledge can easily be codified and transmitted through formal and systematic processes as published knowledge [14]. In contrast, tacit knowledge, with personal contextual expertise, has a cognitive component that intervenes in perception and learning [15].

In the past decade, perhaps the most dramatic evolution in business has been the dawn of the so-called "new economy" based on Internet and information technologies (IT), such as intelligent systems technologies. New economy is established based on an organization successfully shifting its economic value to intellectual assets, assets of information, product distribution, and affiliation. 
In general, an analysis of the literature can identify a set of different approaches for data analysis, whether numerical or text. Essentially, they consign two dimensions of data analysis: linguistic techniques and statistical approaches. Roughly, they can be categorized into several groups based on differences and similarities in their features with each other, i.e., through similarity and nearest-neighbor methods, document similarity, decision rules, decision trees, and probabilities linear scoring methods [16].

Based on Twitter data from a large multinational telecommunication company and 200 managers, with three years of communication data, Fronzetti Colladon and Gloor [17] combined social network analysis (SNA) and text mining to investigate the effect of spammers' activity on the network structure. More recently, given process fragmentation and information exchange among port actors, Aloini et al. [18], by exploiting data from the Port Community Systems, integrated process mining (PM), SNA, and text mining to reconstruct, analyze, and evaluate the information exchange network of the freight export process.

Knowledge creation and knowledge management have been the new goals for organizations that want to increase their competitiveness. Unfortunately, due to a lack of absorptive capacity, many knowledge management projects are, in reality, information systems projects [19-21]. Gold et al. [22] mentioned that knowledge management becomes questionable when the projects only provide some consolidated data but lack innovation that is extended from prior knowledge or innovation which is unprecedented. Overall, to reach knowledge management from information management, in terms of exchange and combination, is a rather complex process that involves developing a knowledge structure that enables organizations to effectively generate knowledge [23-26].

Over the past few decades, there have been many methodologies born for building new knowledge bases, particular in ontologies, from scratch and from existing bases in a variety of settings. Combined with METHONTOLOGY and WebODE, in term of management and support activities, Corcho et al. [27] built a legal entity ontology in the context of the Spanish legal domain. From the viewpoint of knowledge workers on the day-to-day ontology life cycle, Kotis and Vouros [28] presented the human-centered ontology engineering methodology (HCOME) in living ontologies that can accentuate the role of knowledge workers in shaping their information by actively being involved in ontology engineering tasks. In 2011, Villazon-Terrazas et al. [29] developed a network of ontology networks, including local ontology networks and a reference ontology network, using the NeOn methodology to enable an exchange of curricula vitae and job offers in different languages in a semantic interoperability platform. Given existing ontology problems, Sofia Pinto, Tempich, and Staab [30] proposed the DILIGENT methodology that draws domain experts, users, knowledge engineers, and ontology engineers together to collaboratively build an ontology to solve the drawbacks of decentralization, partial autonomy, iteration, and non-expert builders.

There is burgeoning interest in the study of knowledge management which pertains to the interdisciplinary nature of research and practice in decision-making, with particular emphasis on ontology means and methods. From the standpoint of expert knowledge and complying with railway standards, Saa et al. [31] developed an ontology-driven decision support system for designing complex railway problems. Focused on integrating and restructuring methods in the repository, Ziemba et al. [32] adopted the algorithm to build a repository of knowledge about the methods for assessing the quality of a website. To satisfy particular accessibility needs in e-learning contexts, Elias, Lohmann, and Auer [33] presented rule-based queries, in terms of ontology, to retrieve relevant educational resources for learners with disabilities. Traditionally, water pollution accidents have been digitalized through the combination of monitoring sensors, management servers, and application software by adopting mechanistic water-quality models with achieved data. Meng et al. [34] provided the architecture of the ontology-underpinned emergency response system for water pollution accidents to make the water pollution information semantic and the referred applications intelligent. Due to a lack of knowledge systematization in the sustainability assessment domain, Konys [35] contributed knowledge-based 
mechanisms, with formal, practical, and technological guidance, to make the collected knowledge publicly available, reusable, and interoperable.

The growth of the Internet offers enormous potential for professionals and creating a significant body of virtual communities of practice can provide alternative channels for professionals to collaborate with their peers, manage information, and develop and spread knowledge. Research on social interaction falls into three broad categories [36]: (1) connectivity, (2) interactivity, and (3) language use. Through a seven-year longitudinal study with 14,000 members of 16 different healthcare virtual communities of practice, Antonacci et al. [37] pointed out that centralized structure, dynamic leaders, and complex language have driven the growth of the community. Moreover, by enriching the theoretical foundation or framework of knowledge creation and sharing, particularly in an online discussion forum, Barker [38] discovered that, from a continuous basis standpoint, an expert should play a proactive role to ensure new knowledge is created and shared by individuals.

Noy and Musen [39] point out that one of the major shortcomings of the current technology for knowledge-based building is the lack of both reusable and sharable knowledge. Because one must build knowledge bases based on "what one believes" and cannot take into consideration of "justified true beliefs" derived from the actual and potential resources, this increases the difficulty of building knowledge bases. Clearly, facilitating usable and useful knowledge should thus contribute to making it easier to build knowledge bases and fit them into the context within which they must be used. In order to achieve this, Therani [40] and Mizoguchi et al. [41] suggest expertise can be decomposed into a task-dependent but domain-independent portion in which applications can use common data for all domains but not for all tasks and a task-independent but domain-dependent portion in which applications can use common data for all tasks but not for all domains. The former is called "task knowledge", formalized knowledge for an independent problem-solving domain.

\subsection{Task Ontology}

Ontologies has been a field of study with growing importance in the academia from the late twentieth to the early twenty-first century. This phenomenon stems from both their conceptual use in organizing information and their practical use in communicating system characteristics [22,35,42].

In general, an ontology can be viewed as an information model that explicitly describes the various entities and abstractions that exist in a universe of discourse, along with their properties [43,44]. Furthermore, an ontology specifies a conceptual phrase partly to articulate knowledge-level theories of a certain field. From a system standpoint, ontologies provide an overarching framework and vocabulary with which to describe system components and relationships for communicating among architecture and domain areas [45]. Therefore, the more the essence of things is captured, the more possible it is for an ontology to be shared [46-49].

A number of different categorizations of ontologies have been proposed. Van Heijst et al. [50] classify ontologies according to the amount and type of structure of the conceptualization and the subject of the conceptualization, while Guarino [51] distinguishes the type of ontologies by their level of dependence on a particular task or point of view. Subsequently, Lassila and McGuinness [52] group ontologies from the perspective of the information the ontology needs to express and the richness of its internal structure.

Ontologies and problem-solving methods (PSMs), higher-order cognitive processes that require the modulation and control of more routine or fundamental skills, have been created to share and reuse knowledge and reasoning behavior across domains and tasks [20,46]. In general, ontologies are concerned with static domain knowledge, a given specific domain, while PSMs deal with modeling reasoning processes and describing the vocabulary related to a generic task or activity. Benjamins and Gomez-Perez [53] define PSMs as a way of achieving the goal of a task. PSMs have inputs and outputs, and many decompose a task into subtasks, and subtasks into methods. In addition, a PSM specifies the data flow between its subtasks. Guarino [51] defines task ontology as an ontology which formally specifies the terminology associated with a problem type, a high-level generic task which has 
characteristic generic classes of knowledge-based application. Chandrasekaren and Benjamins [54] also define task ontology as "a base of generic vocabulary that organizes the task knowledge for a generic task.". From a problem-solving viewpoint, Newell [55] illustrates that task ontology can be used to model the problem-solving behavior of a task, either at the knowledge level or the symbolic level. Thus, the advantage of task ontology is that it specifies not only a skeleton of the problem-solving process, but also the context in which domain concepts are used. In 2007, Mizoguchi et al. [56] developed an ontology-development tool known as Hozo which has the ability to deal with roles according to their context dependencies. Ikeda et al. [57] suggest that task ontology can be roughly interpreted in two ways: (1) task-subtask decomposition together with task categorization; and (2) an ontology for specifying problem-solving processes. They developed a conceptual level programming environment (CLEPE) based on task ontology in order to make problem-solving knowledge explicit and to exemplify its availability. Rajpathak et al. [58] formalized the task-method-domain-application knowledge modeling framework, which supports both constructing a generic scheduling task ontology to formalize the space of scheduling problems as well as constructing a generic problem-solving model of scheduling that generalizes from the variety of approaches to scheduling problem-solving.

With the volumes of information that continue to increase, the task of turning and integrating this resource dispersed across the Web into a coherent corpus of interrelated information has become a major problem [59]. The emergence of the Semantic Web, providing highly readable data without modifying any of the contents, has shown great promise for the next generation of more capable information technology solutions and mark another stage in the evolution of ontologies and PSMs [46]. Berners-Lee [60] who coined the term Semantic Web, comments that it is envisioned as an extension of the current Web, in which information is given well-defined meaning to better enable computers and people to work in corporations, effectively interweaving human understanding of symbols with machine processability [61]. The way to fulfillment of the corporation can be paved by sharing and re-using domain and task ontologies. The Semantic Web, with domain and task ontologies, can solve some problems much more simply than before and can make it possible to provide certain capabilities that have otherwise been very difficult to support [62-64].

\section{Research Methodology}

In this section we present the TTIPP methodology, which was an integration of task analysis, task ontology, integration definition function modeling (IDEF0), Petri net, and Petri net mark language (PNML), along with the framework shown in Figure 1, to organize and model the task knowledge acquired during the knowledge-acquisition process. The TTIPP methodology is aimed not only at reducing the brittle nature of traditional knowledge-based systems, but also at enhancing knowledge reusability and shareability over different real-world problem-solving applications. Moreover, the proposed model overcomes the drawbacks of IDEF0, namely its static nature and Petri net which has no concept of hierarchy. From the viewpoint of knowledge sharing, the TTIPP methodology can integrate heterogeneous information and distributed information sources to resolve the problems of information access on the Web by translating information into machine processable semantics to facilitate communication between machines and humans.

The TTIPP is composed of three layers and five phases (Figure 1). The top layer, the lexical level model, deals mainly with the syntactic aspect of the problem-solving description in terms of the task analysis phase and task ontology phase. The middle layer, called the conceptual level model, captures the conceptual level meaning of the activity description. The IDEF0 and Petri net models are used in this layer. The bottom layer, called the symbol level model, is the PNML corresponding to the executable program and specifying the computational semantics of problem solving.

This study provides a core epistemology for the knowledge engineer while developing the task ontology for a generic task. The five phases of the proposed integrated model are described in the following sub-sections. 


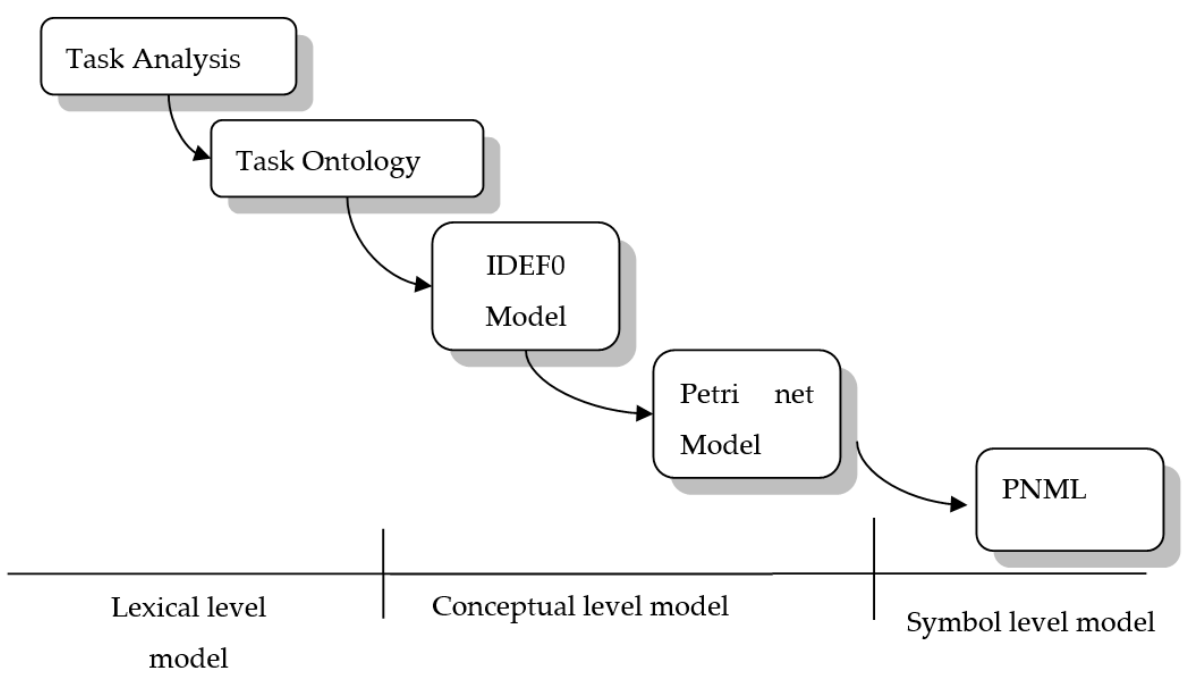

Figure 1. Research framework.

\subsection{Phase-I: Task Analysis}

During the first phase, the nature of a task needs to be thoroughly analyzed at a fine-grained level with diverse informational needs. Structured, semi-structured, or even unstructured knowledge is acquired and elicited from various sources, such as the available literature on the task, the test cases specific to the problem area, the actual interview of the domain experts, one's previous experience in the field, etc. Ikeda et al. [57] divide task analysis into two major steps: (1) rough identification and (2) detailed task analysis.

Based on various sources of knowledge, rough identification of task structure is a classification problem, while detailed task analysis is concerned with interaction with domain experts and then articulating how they perform their tasks. Once various knowledge sources, in terms of a variety of forms, such as document, fact, and records, are analyzed in detail, the important concepts from all of the different classes of application lead to a heightened awareness in such a way that this knowledge provides enough theoretical foundation for expressing the nature of the problem. According to this, the initial focus of the task analysis is to concentrate on the most important concepts around which the task ontology needs to be built

\subsection{Phase-II: Task Ontology}

Detailed categorization of concepts involved is indispensable for task knowledge description. This stage provides a fundamental understanding of the relationships among different concepts. Also, in accordance with the elicited concepts given in the previous phase, this stage provides the ontological engineer with an idea about the important axioms that need to be developed in order to decide on the competence of the task ontology. From the standpoint of granularity and generality, following Ikeda et al. [57], the lexical level task ontology consists of four concepts: (1) generic nouns representing objects reflecting their roles that appear in the problem-solving process; (2) generic verbs representing unit activities that appear in the problem-solving process; (3) generic adjectives and/or adverbs modifying the objects; and (4) generic constraints specific to the task. Figure 2 presents the hierarchy of the lexical level task ontology. 


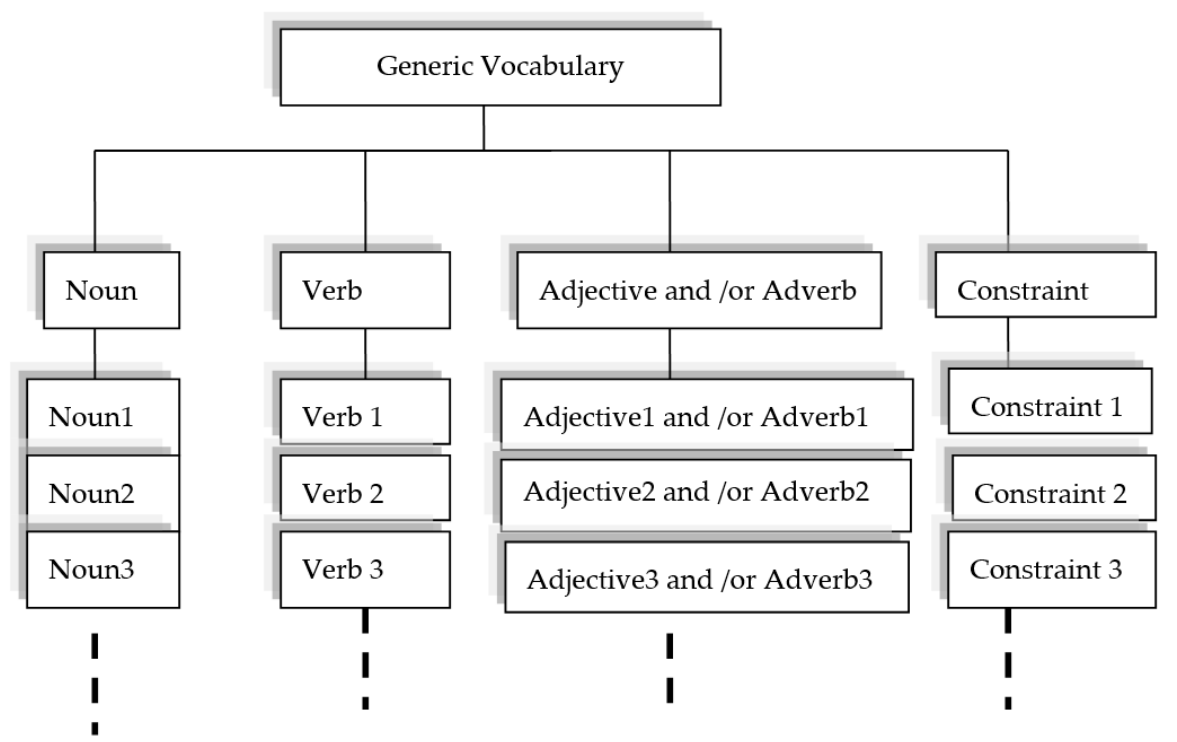

Figure 2. Lexical level of task ontology.

\subsection{Phase-III: IDEF0 Model}

During this phase, task ontology in the research framework can be operationalized by using a formal modeling language tool. IDEF0 is a widely-used, activity-oriented graphic notation and modeling approach for system specification and requirement analysis $[65,66]$. It transforms the concepts described at the natural language level into the formal knowledge modeling level in terms of structured graphical forms. A multi-level model with different classes and relations is created in order to decompose the complex problem into smaller and more detailed sub-problems until the purpose of the model building is reached. An IDEF0 diagram consists of an ordered set of boxes that represent activities performed by a given task. Each box or component in the diagram, representing a given activity, has a simple syntax, shown in Figure 3, with inputs of the activity entering from the left side and the results or outputs of the activity exiting from the right side. The mechanisms, indicated by arrows entering from the bottom of the box, represent resources such as machines, computers, operators, etc. The controls, shown by arrows entering from the top, represent control information, such as parameters and rules of the control systems. The boxes in an IDEF0 diagram, called ICOM for input-control-output-mechanism, are hierarchically decomposed in as many levels as necessary until there is sufficient detail on the basic activities to serve the tasks [21]. The mappings between elements of IDEF0 diagrams and generic vocabularies, from the lexical level to the conceptual level (see Figure 1), are shown in Table 1.

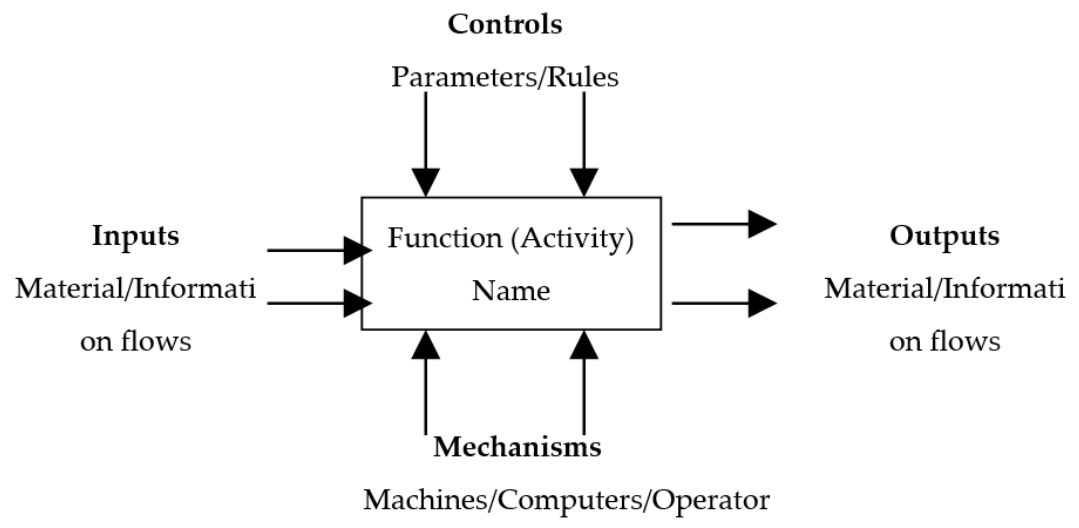

Figure 3. Component of the integration definition function modeling (IDEF0) model. 
Table 1. The mapping between IDEF0 and vocabulary elements.

\begin{tabular}{ll}
\hline \multicolumn{1}{c}{ IDEF0 } & \multicolumn{1}{c}{ Vocabulary } \\
\hline Function & Verb and Noun \\
Input & Noun \\
& (1) Noun \\
& $(2)$ Adjective and Noun \\
Control & $(3)$ Adverb and Adjective and Noun \\
& $(4)$ Constraint and Noun \\
Output & Noun \\
& (1) Noun \\
Mechanism & (2) Constraint and Noun \\
\end{tabular}

\subsection{Phase-IV: Petri Net Model}

Broadly speaking, the IDEF0 model has a number of disadvantages such as its static nature and ambiguity in activity specification [62]. A Petri net consists of three entries: (1) the place, drawn as a circle; (2) the transition, drawn as a bar; and (3) the arcs, connecting places and transitions, as shown in Figure 4a [45]. Known as condition/event nets or place/transition nets, Petri nets are suitable for representation of the structure of hierarchical systems that exhibit concurrency, conflict, and synchronization [67]. To clearly visualize the information flow and control through transitions, a Petri net (PN) allows a place to hold none or a positive number of tokens pictured as small solid dots. Generally, the $\mathrm{PN}$ is defined as quintuple, $\mathrm{PN}=(\mathrm{P}, \mathrm{T}, \mathrm{I}, \mathrm{O}, \mathrm{m})$ [68], where:

$\mathrm{P}=\left\{\mathrm{p}_{1}, \mathrm{p}_{2}, \ldots, \mathrm{p}_{\mathrm{n}}\right\}$ finite set of places; where integer $\mathrm{n}>0$;

$\mathrm{T}=\left\{\mathrm{t}_{1}, \mathrm{t}_{2}, \ldots, \mathrm{t}_{\mathrm{s}}\right\}$ finite set of transitions, where integer $\mathrm{s}>0$, with $\mathrm{P} \cup \mathrm{T} \neq \varnothing$ and

$\mathrm{P} \cap \mathrm{T}=\varnothing ;$

I: $\mathrm{P} \times \mathrm{T} \rightarrow \mathrm{N}$ input incidence function with $\mathrm{n} \times \mathrm{s}$ matrices containing the nonnegative integer that defines the set of directed arcs from $P$ to $T$ where $N=\{0,1,2,3 \ldots \ldots\}$;

$\mathrm{O}: \mathrm{P} \times \mathrm{T} \rightarrow \mathrm{N}$ output incidence function with $\mathrm{n} \times \mathrm{s}$ matrices containing the nonnegative integer that defines the set of directed arcs from $\mathrm{T}$ to $\mathrm{P}$;

$\mathrm{m}: \mathrm{P} \rightarrow \mathrm{N}$ marking vector whose $\mathrm{i}^{\text {th }}$ component represents the number of tokens in the $\mathrm{i}^{\text {th }}$ place. An initial marking is denoted by $\mathrm{m}_{0}$.

The change of system states, called transition firing, will happen by an event when all the input places hold enough number of tokens. Cassandras and Lafortune [69] further explain that a transition is enabled when each input place $P$ of $T$ contains at least a number of tokens equal to the number of the directed arc connecting $P$ to $T$. When an enabled transition $T_{1}$ fires as shown in Figure $4 b$, it removes the token from its input place and deposits it in its output place. Therefore, the execution rules of a PN include enabling and firing rules are shown as follows [68]:

(1) transition $t \varepsilon T$ is enabled if and only if $m(p) \geqq I(p, t), V p \varepsilon P$

(2) enabled in a marking $\mathrm{m}, \mathrm{t}$ fires and results in a new marking $\mathrm{m}^{\prime}$ following the rules:

$$
\begin{aligned}
\mathrm{m}^{\prime}(\mathrm{p}) & =\mathrm{m}(\mathrm{p})-\mathrm{I}(\mathrm{p}, \mathrm{t})+\mathrm{O}(\mathrm{p}, \mathrm{t}) \\
& =\mathrm{m}(\mathrm{p})+\mathrm{C}(\mathrm{p}, \mathrm{t}), \mathrm{Vp \varepsilon} \mathrm{P}
\end{aligned}
$$

where $\mathrm{C}=\mathrm{O}-\mathrm{I}$ and $\mathrm{m}^{\prime}$ is said to be immediately reachable from $\mathrm{m}$. 
$\mathrm{T}_{1}$

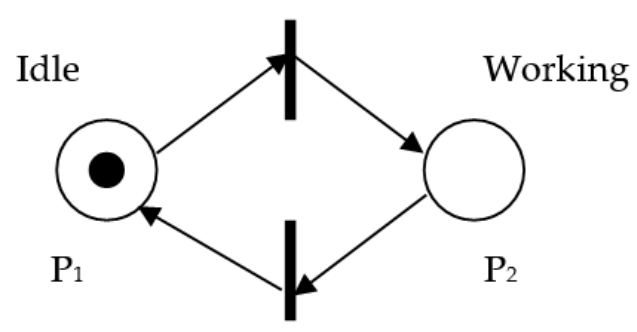

$\mathrm{T}_{2}$

(a)
$\mathrm{T}_{1}$

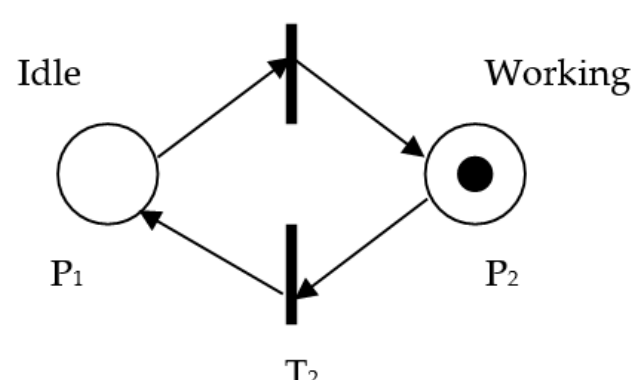

(b)

Figure 4. Component of a Petri net. (a) The token in its input place. (b) The token transfer into its output place.

Murata [70] presents invariant analysis methods, including P-invariant and T-invariant, to govern the dynamic behavior of concurrent systems modeled by Petri nets. He calls $\mathrm{C}=\mathrm{O}-\mathrm{I}$ an incidence matrix, to prove that subsets of places over which the sum of the tokens may remain unchanged (P-invariant) and a transition firing sequence brings the marking back to the same one (T-invariant). In writing matrix equations, Murata [70] describes the execution rules as abiding by the following equation:

$$
\mathrm{m}_{\mathrm{k}}=\mathrm{m}_{\mathrm{k}-1}+\mathrm{C}_{\mathrm{uk}} \quad \mathrm{k}=1,2,3 \ldots .
$$

where $m_{k}$ donates a marking immediately reachable from marking $m_{k-1}$. The $k^{\text {th }}$ firing vector or $u_{k}$ is an $s \times 1$ column vector and the $i^{\text {th }}$ column of $C$ represents a change of a marking if transition $t_{i}$ fires at the $\mathrm{k}^{\text {th }}$ firing, and then the $\mathrm{i}^{\text {th }}$ position of $\mathrm{u}_{\mathrm{k}}$ is 1 and the other positions are filled with $0 \mathrm{~s}$. He further defines a P-invariant of the nonzero nonnegative integer solution $x$ of $C^{T} x=0$, then, the previously stated equation is rewritten as follows:

$$
\mathrm{x}^{\mathrm{T}} \mathrm{m}_{\mathrm{k}}=\mathrm{x}^{\mathrm{T}} \mathrm{m}_{\mathrm{k}-1}+\mathrm{x}^{\mathrm{T}} \mathrm{C}_{\mathrm{uk}} \quad \mathrm{k}=1,2,3 \ldots \ldots
$$

Since $C^{T} x=0$, thus $x^{T} C=0$, then

$$
\mathrm{x}^{\mathrm{T}} \mathrm{m}_{\mathrm{k}}=\mathrm{x}^{\mathrm{T}} \mathrm{m}_{\mathrm{k}-1} \quad \mathrm{k}=1,2,3 \ldots .
$$

Therefore, $x^{T} m_{k}=x^{T} m_{k-1}=$ constant.

He also defines the nonzero nonnegative solution $\mathrm{y}$ of $\mathrm{Cy}=0$ as a T-invariant associated with firing a sequence of transitions, leading $\mathrm{m}_{\mathrm{o}}$ back to $\mathrm{m}_{0}$, and the $\mathrm{i}^{\text {th }}$ element of the aggregate firing vector $u$ being the number of $t_{i} s$ firing times in the sequence. Clearly, based on the equation $m_{0}=m_{0}$ $+\mathrm{C}_{\mathrm{u}}, \mathrm{C}_{\mathrm{u}}=0$ and $\mathrm{u}$ is a T-invariant.

To transform static models generated by the IDEF0 method into a dynamic PN model, Santarek and Buseif [21] developed the following transformation rules:

$\operatorname{Tr}_{1}$ : If activities exist, then transform them into a Petri net sequence: transition-place-transition.

$\mathrm{Tr}_{2}$ : If arrow outputs exist, then form PN place with tokens in them.

$\mathrm{Tr}_{3}$ : (1) If shared mechanisms exist, then form PN place with tokens in them.

(2) If a shared mechanism decomposed into a sub-mechanism exists, then there is no generation of $\mathrm{PN}$ place.

$\mathrm{Tr}_{4}$ : If all mechanisms used in the PN do not exist in any IDEF0 diagram, then transformation is completed.

The relationships, from a static perspective to dynamic viewpoint, between IDEF0 diagrams and Petri net components are presented in Table 2 [67]. 
Table 2. The relationship between Petri Net and IDEF0 components.

\begin{tabular}{cc}
\hline IDEF0 & Petri Net \\
Activity (box) & $\begin{array}{c}\text { PN place (condition) with two } \\
\text { Petri net transitions (start and } \\
\text { finished events) } \\
\text { Place }\end{array}$ \\
Onput (arrow) & Place \\
Cutput (arrow) & Place \\
Mechanism (arrow) & Place
\end{tabular}

\subsection{Phase-V: Petri Net Markup Language}

The Petri net markup language (PNML) is an extensible markup language (XML) based on interchangeable formats for Petri nets. The PNML is designed to be a Petri net interchange format that is independent of specific tools and platforms. Moreover, the interchange format needs to support different dialects of Petri nets and must be extensible. Thus, PNML should necessarily include the following essential characteristics [71]: (1) Flexibility to represent any kind of Petri net with its specific extensions and features, (2) assurance to remove ambiguity for uniquely determining its PNML representation, and (3) compatibility to exchange as much information as possible between different types of Petri nets.

Even with a mature development of Petri net technology, it is difficult to know what is possible in the future. Certainly, PNML should shed light on the definition of Petri net types to support different versions of Petri nets and, in particular, future versions of Petri nets. Given the above-mentioned information, PNML is adopted as a starting point for a standard interchange format for Petri nets. For implementing purposes, XML was used for its platform, independent in terms of having many tools available for reading, writing, and validating. Table 3 presents the translation of the PNML meta model into XML elements, along with the attributes and their data types.

Table 3. Translation of the Petri net mark language (PNML) meta model into extensible markup language (XML) elements and attributes.

\begin{tabular}{lll}
\hline \multicolumn{1}{c}{ Class } & \multicolumn{1}{c}{ XML Elements } & \multicolumn{1}{c}{ XML Attributes } \\
\hline PetriNetFile & $<$ pnml $>$ & id: ID \\
PetriNet & $<$ net $>$ & type: anyURL \\
Place & $<$ place $>$ & id: ID \\
Transition & $<$ transition $>$ & id: ID \\
& id: ID \\
Arc & $<$ arc $>$ & source: IDRef (Node) \\
& & traget: IDRef (Node) \\
Page & $<$ page $>$ & id: ID \\
RefPlace & $<$ id: ID \\
& & ref: IDRef (Place or RefPlace) \\
RefTrans & $<$ referenceTransition $>$ & id: ID \\
& ref: IDRef (Transition or RefTrans) & tool: string \\
ToolInfo & $<$ toolspecific $>$ & version: string \\
Graphics & $<$ graphics $>$ & \\
\hline
\end{tabular}




\section{An Example Application}

The development of an incident command system (ICS) for a natural disaster requires collaboration and participation at the national level, as well as the local community level. TTIPP methodology not only could help to integrate heterogeneous and distributed information sources with machine processable semantics, but also could help users browse the information based on semantics with common understanding to achieve the knowledge sharing purpose.

As an example application, the TTIPP model presented in this paper was used for management of the knowledge of debris-flow during typhoons in the past three decades in the area of Homchu in Nantou county located in Central Taiwan. Homchu village is located at an altitude of 550 to $750 \mathrm{~m}$. It is connected to Mingde village in the north, Tongfu village in the south, and Chenyoulan River in the west (see Figure 5). There are over 70 families, with 451 males and 370 females, in the village and they plant grape orchards as their main source of income. The village was the site of significant damage resulting from the earthquake on September 21st, 1999. Such typhoons and the resulting debris flow originating from the mountainous region are an annual occurrence on the Chenyoulan River in the region. The Homchu community activity center, elementary school, and church are the main distribution centers when it comes to disaster prevention and refuge in the village. Prior to a disaster, they store refuge materials and prepare temporary shelters and medical emergency stations. The main task is to protect the public from debris flow, which includes water, rocks, soil, and tree trunks and it is divided into four subtasks: mitigation, preparedness, response, and post-disaster reconstruction. The subtasks correspond with the rough identification steps of Ikeda et al. [57].

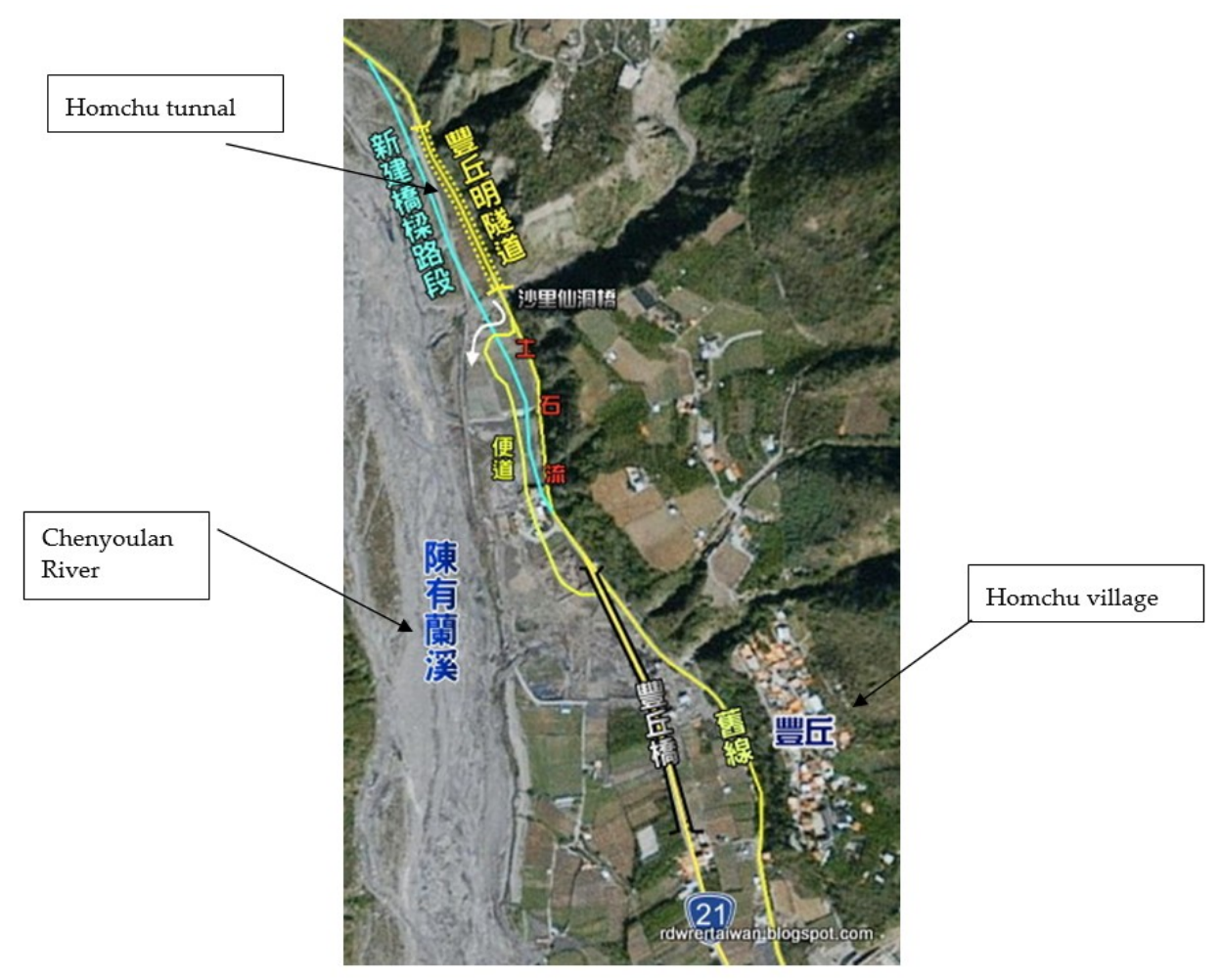

Figure 5. Study area.

\subsection{Phase-I: Task Analysis}

Based on the available literature on the task, an open-ended interview questionnaire, in terms of how, when, who, what, how many, and why, specific to the aforementioned subtasks was designed and the six stakeholders (different teams or domain experts) involved in the ICS operations were invited to share their experience and reconfirm the content of their interviews which were recorded 
and transferred verbatim for future analysis. Table 4 shows the profile of domain experts, along with their numbers of years of experience with the ICS for debris-flow management during typhoons.

Table 4. Profile of domain experts.

\begin{tabular}{lcc}
\hline \multicolumn{1}{c}{ Team } & Responsibility & $\begin{array}{c}\text { Number of Years of } \\
\text { Experience with ICS }\end{array}$ \\
\hline 1. Homchu Village Captain & Leader & 9 years \\
2. Monitor and alert & Sub-Leader & 5 years \\
3. Equipment and food supply management & Sub-Leader & 9 years \\
4. Evacuation and accommodation & Sub-Leader & 2 years \\
5. Urgent repair on structures & Sub-Leader & 9 years \\
6. Emergency rescue, health, and sanitation & Sub-Leader & 9 years \\
\hline
\end{tabular}

The tasks of the different teams are described briefly below:

1. Homchu village captain team: (1) Inform the sub-group teams to gather at the activity center. (2) Open a command center. (3) Command the execution of disaster relief tasks in each sub-group. (4) Request for assistance from outside. (5) Instruct the establishment of the shelter. (6) Command the rescue sub-group to prepare for the initial rescue and on-site rescue. (7) Report statistics on casualties. (8) Contact the ambulance staff and go to each shelter.

2. Monitor and alert team: (1) Examine, judge, and monitor the content and objects of the disaster. (2) Community security maintenance, disaster area control, and traffic guidance. (3) Monitor the disaster site. (4) Conduct evacuation guidance for sub-group members.

3. Equipment and food supply management team: (1) Supply of disaster relief food and water and warm clothing. (2) Provide rescue equipment. (3) Support and manage disaster relief materials and equipment from inside and outside of the community.

4. Evacuation and accommodation team: (1) Inform the responsible personnel of each district to be in place. (2) Monitor pre-set shelters to prepare for housing. (3) Inform everyone of temporary shelter and social assistance for residents. (4) Register and manage personnel in the shelter.

5. Urgent repair of structures team: (1) Collect rescue crew and equipment to go to the scene for initial rescue. (2) Deploy large equipment. (3) Rescue of victims. (4) Prevent the expansion of derivative disasters. (5) Report the rescue process to the command center.

6. Emergency rescue, health, and sanitation team: (1) Open a simple medical service station. (2) On-site emergency rescue work for the victims. (3) Send the victims to the hospital. (4) Register the casualties.

Interviews with domain experts constitute the detailed task analysis step mentioned earlier.

\subsection{Phase-II: Task Ontology}

The task knowledge of ICS operations from a variety of sources such as the available literature and the interview with the domain experts was analyzed for the lexical level task ontology. The four ICS stages were denoted as: mitigation (A1), preparedness (A2), response (A3), and post-disaster reconstruction (A4). Due to the complexity and the dynamic nature of problem-solving methods for ICS and space limitations, only the results for emergency response (A3) of debris flow were chosen to serve as an example for presenting the TTIPP framework. Focusing only on the important concepts of task analysis, Table 5 partially illustrates the generic vocabulary for describing the structure of ICS knowledge classified into nouns, verbs, adjectives, adverbs, and constraints. 
Table 5. Vocabulary list of the incident command system (partial).

\begin{tabular}{|c|c|c|c|c|c|}
\hline \multirow{4}{*}{ Noun } & \multirow[t]{2}{*}{ People } & \multirow[t]{2}{*}{$\begin{array}{l}\text { Civil defense } \\
\text { refuge } \\
\text { victim }\end{array}$} & \multirow{4}{*}{ Noun } & \multirow[t]{2}{*}{ Place } & $\begin{array}{l}\text { church } \\
\text { village }\end{array}$ \\
\hline & & & & & Diesel oil \\
\hline & Information & $\begin{array}{l}\text { Weather } \\
\text { information }\end{array}$ & & \multirow{2}{*}{ Material } & Cellular phone \\
\hline & & $\cdots \cdots$ & & & $\ldots \ldots$ \\
\hline \multirow{3}{*}{ Verb } & observe & & \multirow{3}{*}{ Verb } & announce & \\
\hline & patrol & & & inspect & \\
\hline & $\cdots$ & & & $\ldots \ldots$ & \\
\hline \multirow{3}{*}{ Adjective } & hourly & & \multirow{3}{*}{ Adjective } & small & \\
\hline & compulsory & & & weak & \\
\hline & $\cdots \cdots$ & & & $\cdots \cdots$ & \\
\hline \multirow{2}{*}{ Adverb } & \multirow{2}{*}{\multicolumn{2}{|c|}{$\begin{array}{l}\text { completely } \\
\ldots \ldots\end{array}$}} & \multirow{2}{*}{ Adverb } & urgently & \\
\hline & & & & $\cdots \cdots$ & \\
\hline \multirow[t]{2}{*}{ Constraint } & \multicolumn{2}{|c|}{$\begin{array}{l}\text { Hourly rainfall reaching } 200 \mathrm{~mm} \\
\text { (yellow alert) }\end{array}$} & \multirow[t]{2}{*}{ Constraint } & \multicolumn{2}{|c|}{$\begin{array}{l}\text { Hourly rainfall reaching } 300 \mathrm{~mm} \\
\text { (red alert) }\end{array}$} \\
\hline & $\ldots \ldots \ldots$ & & & $\ldots \ldots \ldots$ & \\
\hline
\end{tabular}

\subsection{Phase-III: IDEF0 Model}

At the modeling stage, an IDEF0 model was built for describing the function of the emergency response (A3). From a functional point of view, the present emergency response had six activities as shown in Figure 6. They were "Establish an advance command post"(A31), "Monitor any possible disaster locations"(A32), "Evacuate residents"(A33), “Urgent repair of structure"(A34), “Emergency rescue of people"(A35) and "Manage goods and materials" (A36). The ICOM of emergency response is presented in Table 6 . For the purpose of making it simple to understand, the hierarchical decomposition of each activity into sub-activities was performed to reveal more detail at each level as shown in Figures 7-12.

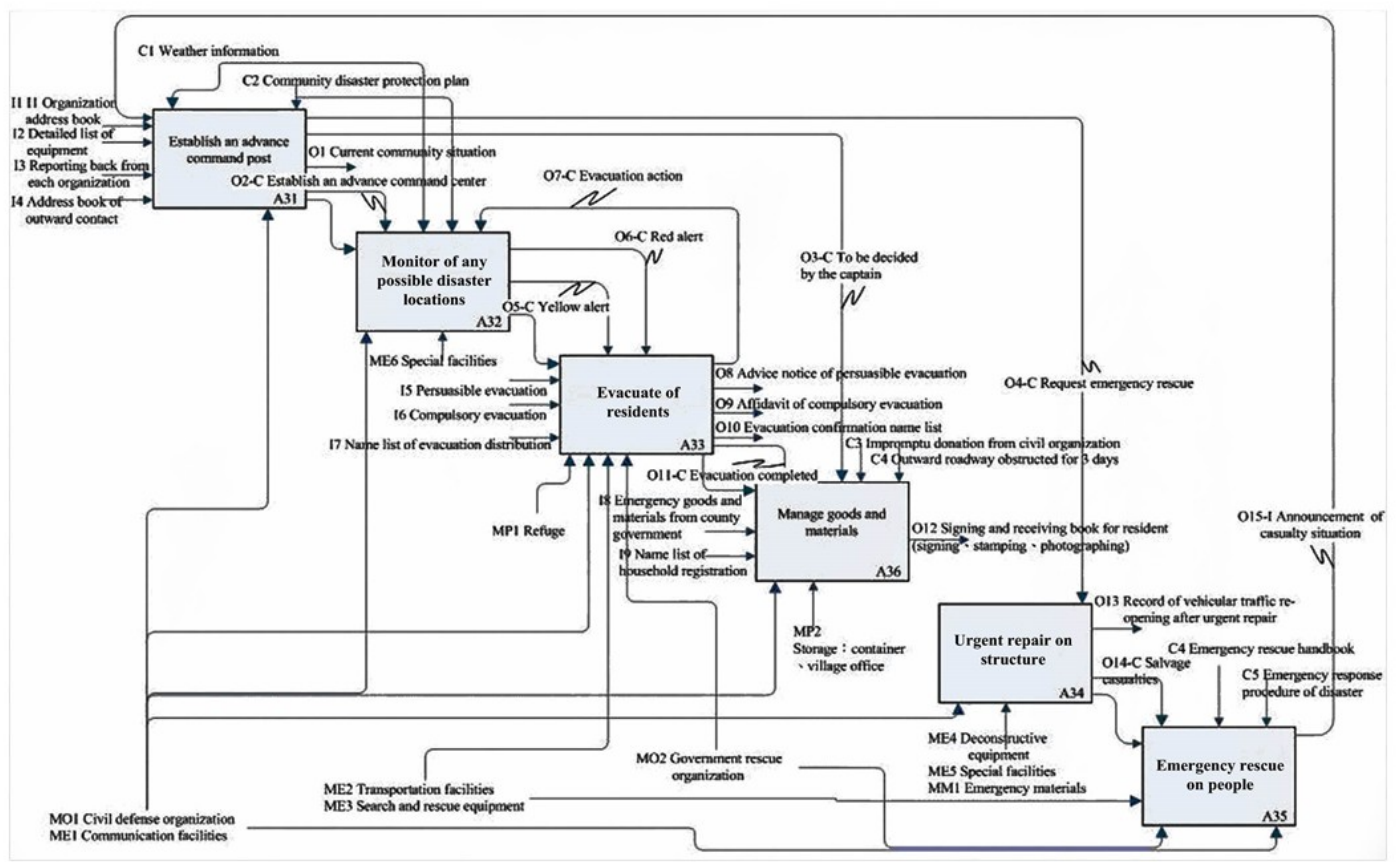

Figure 6. The IDFE0 model of the "emergency response" (A3). 
Table 6. The input-control-output-mechanism (ICOM) of "Emergency response" (A3).

\begin{tabular}{|c|c|c|c|c|c|}
\hline Activity & Sub-Activity & Input & Control & Output & Mechanism \\
\hline \multirow{4}{*}{ A3 Emergency response } & $\begin{array}{l}\text { A31 Establish an } \\
\text { advance command post }\end{array}$ & $\begin{array}{l}\text { I1 Organization address } \\
\text { book } \\
\text { I2 Detailed list of } \\
\text { equipment } \\
\text { I3 Reporting back from } \\
\text { each organization } \\
\text { I4 Address book of } \\
\text { outward contact } \\
\text { O15-I Announcement of } \\
\text { casualty situation }\end{array}$ & $\begin{array}{l}\text { C1 Weather information } \\
\text { 1. Start announcement of disaster } \\
\text { emergency response system } \\
\text { 2. Start announcement of disaster } \\
\text { emergency response system } \\
\text { 3. Average hourly rainfall } \\
\text { (200 mm }) \\
\text { 4. } 2 \text { Community disaster } \\
\text { protection plan }\end{array}$ & $\begin{array}{l}\text { O1 Current community } \\
\text { situation } \\
\text { O2-C Establish an } \\
\text { advance command center } \\
\text { O3-C To be decided by the } \\
\text { captain } \\
\text { O4-C Request emergency } \\
\text { rescue }\end{array}$ & $\begin{array}{l}\text { MO1 Civil defense } \\
\text { organization } \\
\text { ME1 Communication } \\
\text { facilities }\end{array}$ \\
\hline & \multirow[b]{2}{*}{$\begin{array}{l}\text { A32 Monitor of any } \\
\text { possible disaster } \\
\text { locations }\end{array}$} & & C1 Weather information & & \multirow[b]{2}{*}{$\begin{array}{l}\text { MO1 Civil defense } \\
\text { organization } \\
\text { ME1 Communication } \\
\text { facilities } \\
\text { ME6 Special facilities }\end{array}$} \\
\hline & & & $\begin{array}{l}\text { 1. Start announcement of disaster } \\
\text { emergency response system } \\
\text { 2. Start announcement of debris } \\
\text { flow monitoring system } \\
\text { 3. Average hourly rainfall } \\
\quad(200 \mathrm{~mm}) \\
\text { C2 Community disaster protection } \\
\text { plan } \\
\text { O2-C Establish an advance command } \\
\text { center } \\
\text { O7-C Evacuation action completed }\end{array}$ & $\begin{array}{l}\text { O5-C Yellow alert } \\
\text { O6-C Red alert }\end{array}$ & \\
\hline & A33 Evacuate residents & $\begin{array}{l}\text { I5 Persuasible evacuation } \\
\text { I6 Compulsory evacuation } \\
\text { I7 Name list of evacuation } \\
\text { distribution }\end{array}$ & $\begin{array}{l}\text { O5-C Yellow alert } \\
\text { O6-C Red alert }\end{array}$ & $\begin{array}{l}\text { O7-C Evacuation action } \\
\text { O8 Advice notice of } \\
\text { persuasible evacuation } \\
\text { O9 Affidavit of } \\
\text { compulsory evacuation } \\
\text { O10 Evacuation } \\
\text { confirmation name list } \\
\text { O11-C Evacuation } \\
\text { completed }\end{array}$ & $\begin{array}{l}\text { MO1 Civil defense } \\
\text { organization } \\
\text { MO2 Government rescue } \\
\text { organization } \\
\text { ME1 Communication } \\
\text { facilities } \\
\text { ME2 Transportation facilities } \\
\text { ME3 Search and rescue } \\
\text { equipment } \\
\text { MP1 Refuge }\end{array}$ \\
\hline
\end{tabular}


Table 6. Cont

\begin{tabular}{|c|c|c|c|c|c|}
\hline Activity & Sub-Activity & Input & Control & Output & Mechanism \\
\hline & $\begin{array}{l}\text { A34 Urgent repair on } \\
\text { structure }\end{array}$ & & O4-C Request emergency repair & $\begin{array}{l}\text { O13 Record of vehicular } \\
\text { traffic re-opening after } \\
\text { urgent repair } \\
\text { O14-C Salvage casualties }\end{array}$ & $\begin{array}{l}\text { MO1 Civil defense } \\
\text { organization } \\
\text { ME1 Communication } \\
\text { facilities } \\
\text { ME4 Deconstructive } \\
\text { equipment } \\
\text { ME5 Special facilities } \\
\text { MM1 Emergency materials }\end{array}$ \\
\hline & $\begin{array}{l}\text { A35 Emergency rescue of } \\
\text { people }\end{array}$ & & $\begin{array}{l}\text { O14-C Salvage casualties } \\
\text { C4 Emergency rescue handbook } \\
\text { C5 Emergency response procedure of } \\
\text { disaster }\end{array}$ & $\begin{array}{l}\text { O15-I Announcement of } \\
\text { casualty situation }\end{array}$ & $\begin{array}{l}\text { MO1 Civil defense } \\
\text { organization } \\
\text { MO2 Governmental rescue } \\
\text { organization } \\
\text { ME1 Communication } \\
\text { facilities } \\
\text { ME2 Transportation facilities } \\
\text { ME3 Search and rescue } \\
\text { equipment }\end{array}$ \\
\hline & $\begin{array}{l}\text { A36 Manage goods and } \\
\text { materials }\end{array}$ & $\begin{array}{l}\text { I8 Emergency goods and } \\
\text { materials from county } \\
\text { government } \\
\text { I9 Name list of household } \\
\text { registration }\end{array}$ & $\begin{array}{l}\text { O3-C To be decided by the captain } \\
\text { O11-C Evacuation completed } \\
\text { C3 Impromptu donation from civil } \\
\text { organization } \\
\text { C4 Outward roadway obstructed for } \\
3 \text { days }\end{array}$ & $\begin{array}{l}\text { O12 Signing and receiving } \\
\text { book for resident } \\
\text { (signing, stamping, } \\
\text { photographing) }\end{array}$ & $\begin{array}{l}\text { MO1 Civil defense } \\
\text { organization } \\
\text { ME1 Communication } \\
\text { facilities } \\
\text { MP2 Storage: container- } \\
\text { village office }\end{array}$ \\
\hline
\end{tabular}




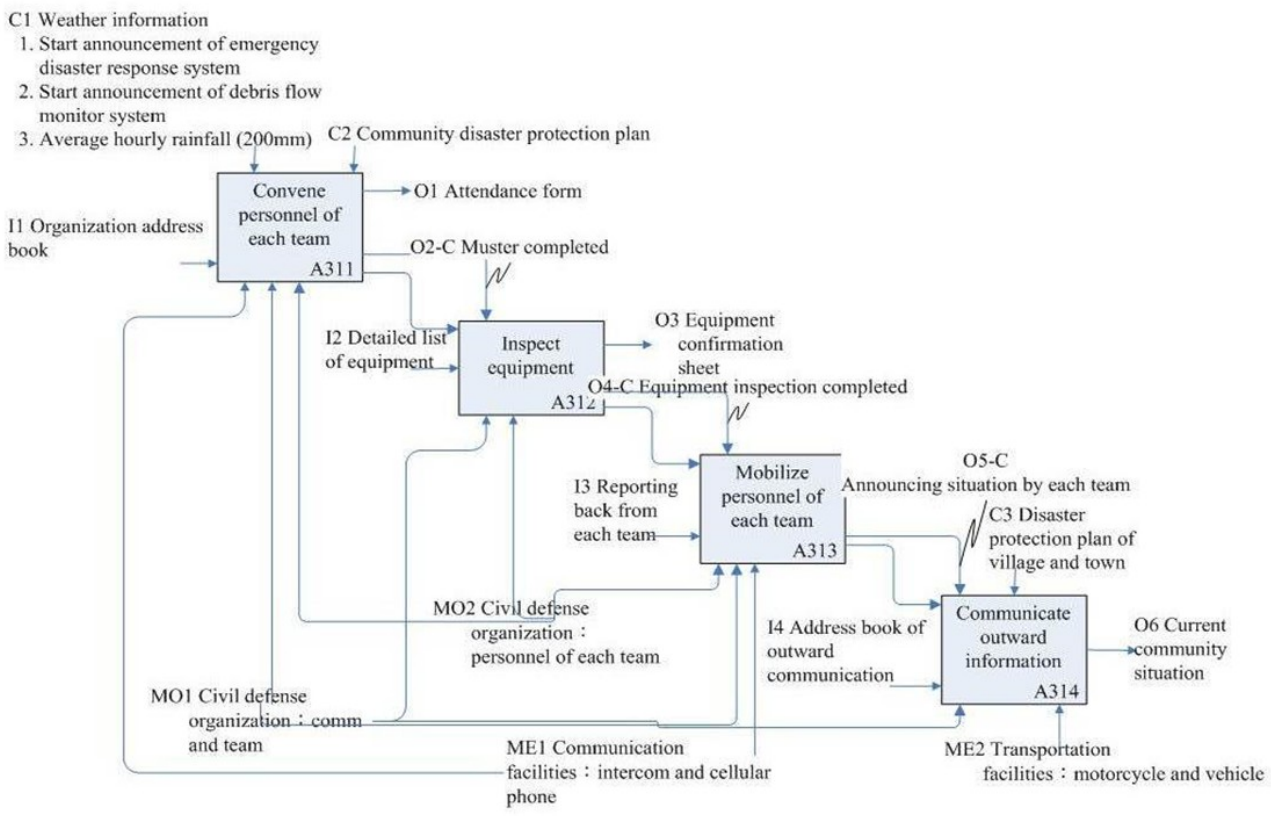

Figure 7. The IDFE0 model of the "Establish an advance command post" (A31).

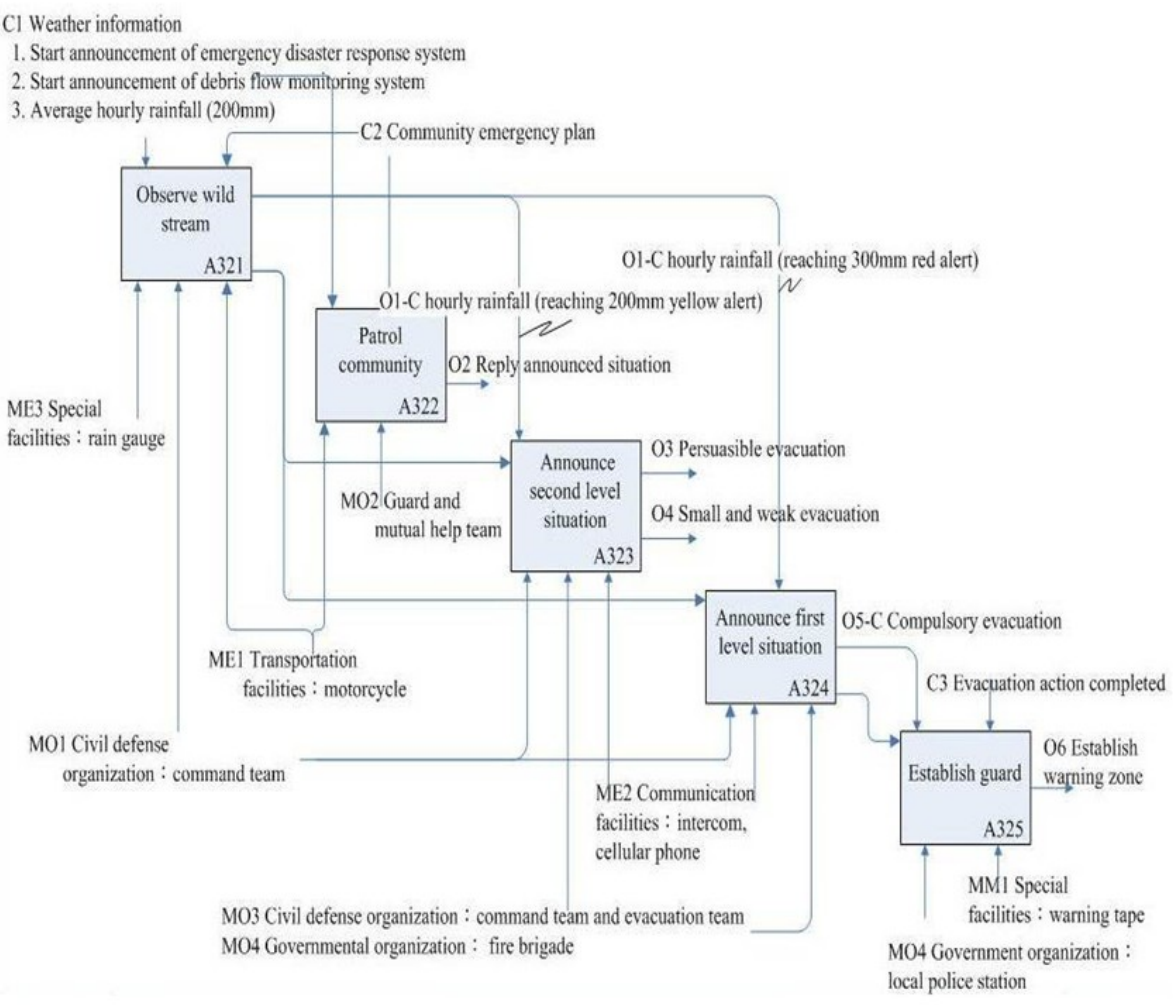

Figure 8. The IDFE0 model of the "“Monitor any possible disaster locations" (A32). 


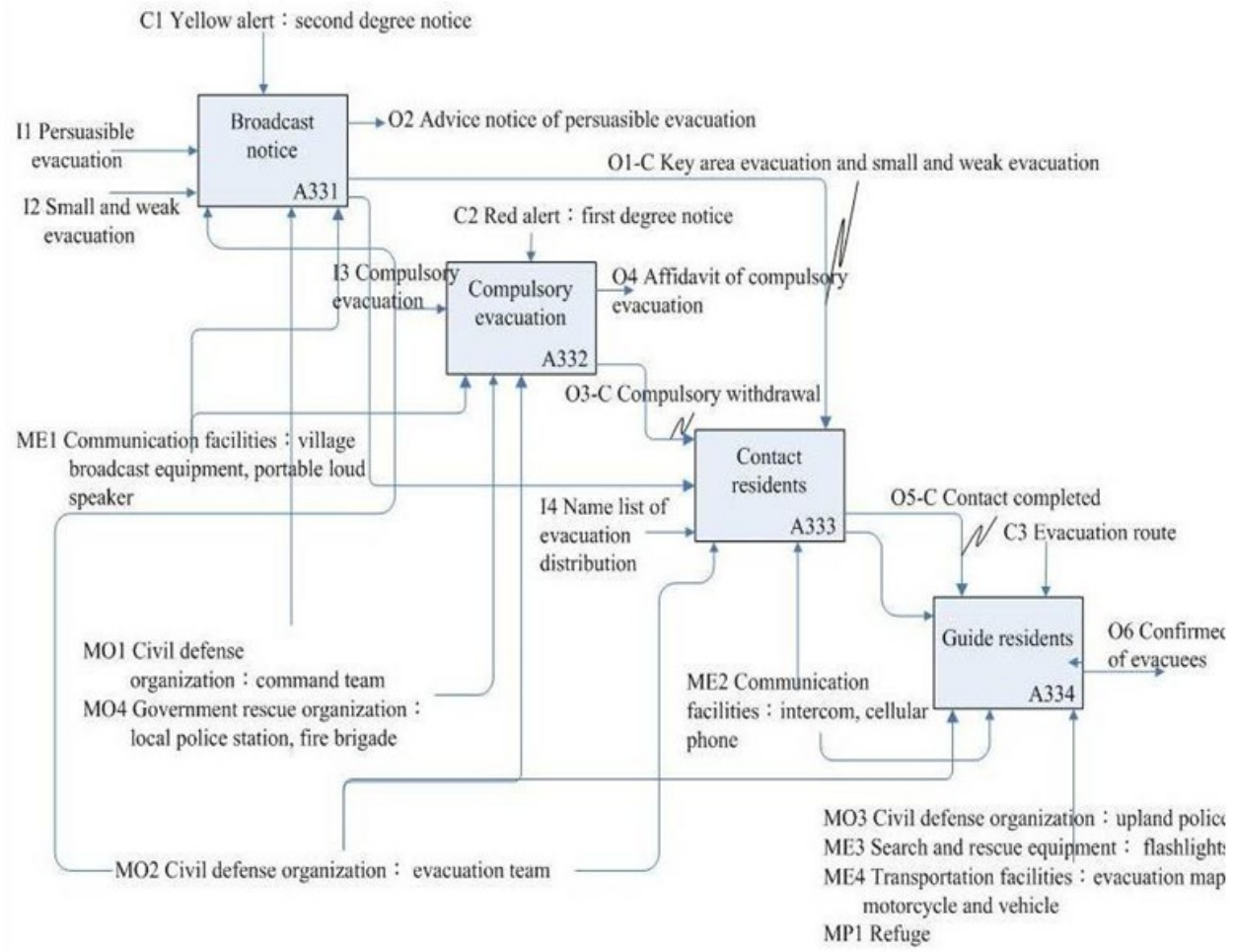

Figure 9. The IDFE0 model of the "Evacuate of residents" (A33).

$\mathrm{Cl}$ Request urgent repair

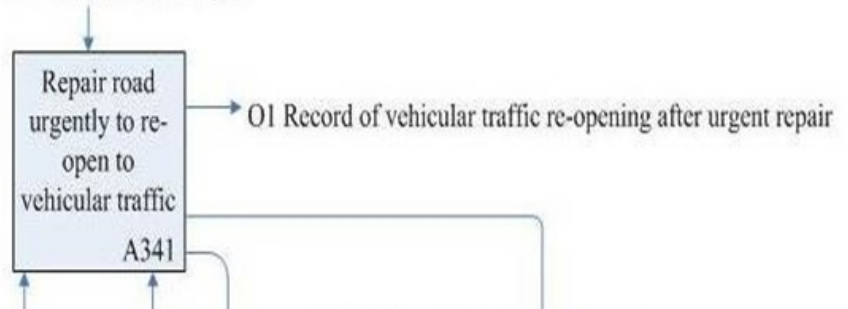

MMI Emergency materials : diesel oil

ME1 Deconstructive equipment : motor shovel, excavator

ME2 Communication facilities : intercom, cellular phone

ME3 Special facilities : generator

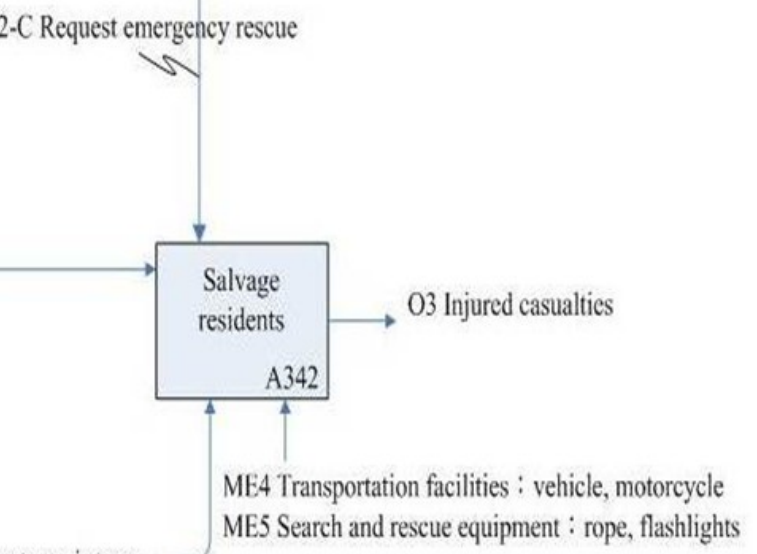

MOI Civil defense organization : construction urgent repair team

ME5 Search and rescue equipment : rope, flashlights

Figure 10. The IDFE0 model of the "Urgent repair of structure" (A34). 


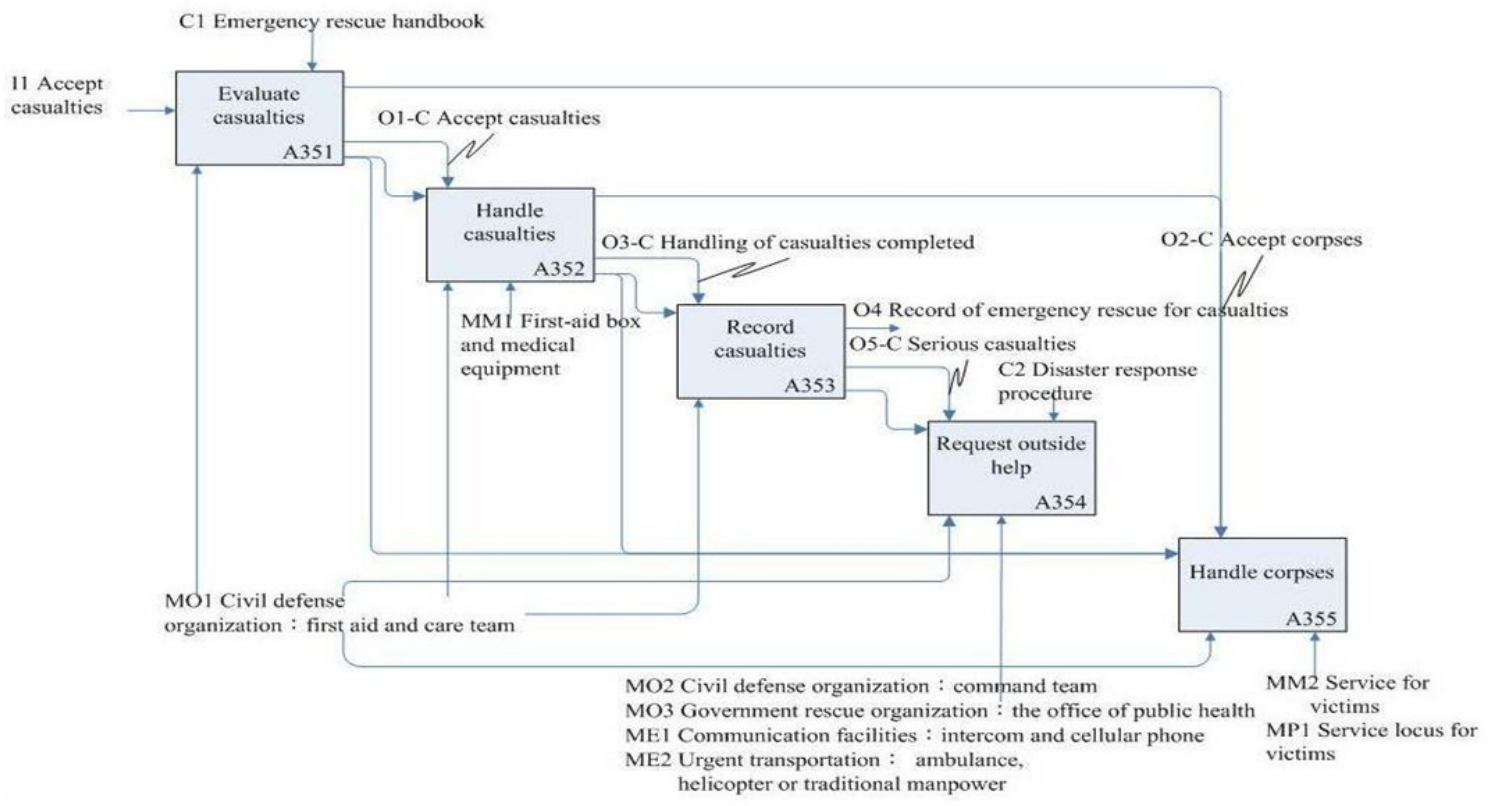

Figure 11. The IDFE0 model of the "Emergency rescue of people" (A35).

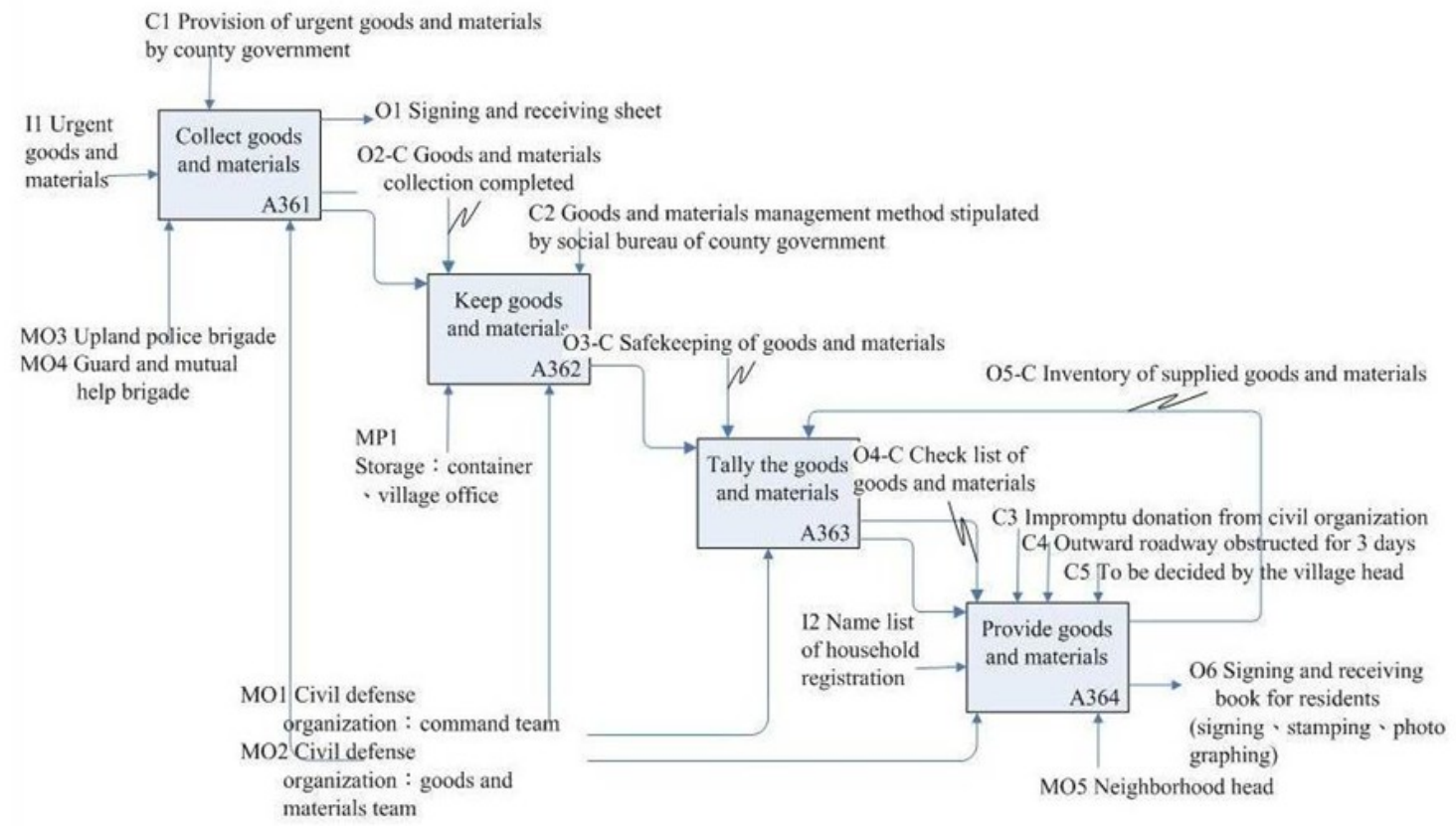

Figure 12. The IDFE0 model of the "Manage goods and materials" (A36).

"Monitor any possible disaster locations" (A32) was decomposed into five sub-activities, as shown in Figure 8: "Observe wild stream" (A321), "Patrol community" (A322), "Announce first level situation", (A323), "Announce second level situation" (A324), and "Establish guard" (A325), and its ICOM shown in Table 7. The different mechanisms support different sub-activities as shown in Figure 8. For example, the "Observe wild stream" (A321) and "Patrol community" (A322) were controlled by the "Weather information" (C1) and "Community emergency plan" (C2), while "Establish guard" (A325) was controlled by the "evacuation action completed" (C3). After obtaining the functional IDEF0 model, we then developed the Petri net model for behavior analysis at the next stage. 
Table 7. The ICOM of "Monitor of any possible disaster location" (A32).

\begin{tabular}{|c|c|c|c|c|c|}
\hline Activity & Sub-Activity & Input & Control & Output & Mechanism \\
\hline \multirow{9}{*}{$\begin{array}{l}\text { A32 Monitor of any } \\
\text { possible disaster } \\
\text { locations }\end{array}$} & \multirow{3}{*}{$\begin{array}{l}\text { A321 Observe } \\
\text { wild stream }\end{array}$} & & C1 Weather information & \multirow{3}{*}{$\begin{array}{l}\text { O1-C hourly rainfall } \\
\text { (reaching } 200 \mathrm{~mm} \text { yellow } \\
\text { alert) } \\
\text { O1-C hourly rainfall } \\
\text { (reaching } 300 \mathrm{~mm} \text { red } \\
\text { alert) }\end{array}$} & \multirow{3}{*}{$\begin{array}{l}\text { MO1 Civil defense organization: } \\
\text { command team } \\
\text { ME1 Transportation facilities: motorcycle } \\
\text { ME3 Special facilities: rain gauge }\end{array}$} \\
\hline & & & $\begin{array}{l}\text { 1. Start announcement of emergency } \\
\text { disaster response system } \\
\text { 2. Start announcement of debris flow } \\
\text { monitoring system } \\
\text { 3. Average hourly rainfall }(200 \mathrm{~mm})\end{array}$ & & \\
\hline & & & C2 Community emergency plan & & \\
\hline & \multirow{3}{*}{\multicolumn{2}{|c|}{$\begin{array}{l}\text { A322 Patrol } \\
\text { community }\end{array}$}} & C1 Weather information & \multirow{3}{*}{$\begin{array}{l}\text { O2 Reply announced } \\
\text { situation }\end{array}$} & \multirow{3}{*}{$\begin{array}{l}\text { MO2 Guard and mutual help team } \\
\text { ME1 Transportation facilities: motorcycle }\end{array}$} \\
\hline & & & $\begin{array}{l}\text { 1. Start announcement of emergency } \\
\text { disaster response system } \\
\text { 2. Start announcement of debris flow } \\
\text { monitoring system }\end{array}$ & & \\
\hline & & & C2 Community emergency plan & & \\
\hline & $\begin{array}{l}\text { A323 Announce } \\
\text { second degree } \\
\text { situation }\end{array}$ & & $\begin{array}{l}\text { O1-C Hourly rainfall reaching } 200 \mathrm{~mm} \\
\text { (yellow alert) }\end{array}$ & $\begin{array}{l}\text { O3 Persuasible evacuation } \\
\text { O4 Small and weak } \\
\text { evacuation }\end{array}$ & $\begin{array}{l}\text { MO1 Civil defense organization: } \\
\text { command team } \\
\text { MO3 Civil defense organization: } \\
\text { command team and evacuation team } \\
\text { MO4 Governmental organization: fire } \\
\text { brigade } \\
\text { ME2 Communication facilities: intercom, } \\
\text { cellular phone }\end{array}$ \\
\hline & \multicolumn{2}{|l|}{$\begin{array}{l}\text { A324 Announce } \\
\text { first degree } \\
\text { situation }\end{array}$} & $\begin{array}{l}\text { O2-C Hourly rainfall reaching } 300 \mathrm{~mm} \text { (red } \\
\text { alert) }\end{array}$ & $\begin{array}{l}\text { O5-C Compulsory } \\
\text { evacuation }\end{array}$ & $\begin{array}{l}\text { MO1 Civil defense organization: monitor } \\
\text { team } \\
\text { MO3 Civil defense organization: } \\
\text { command team and evacuation team } \\
\text { MO4 Government organization: fire } \\
\text { brigade } \\
\text { ME2 Communication facilities: intercom, } \\
\text { cellular phone }\end{array}$ \\
\hline & \multicolumn{2}{|l|}{$\begin{array}{l}\text { A325 Establish } \\
\text { guard }\end{array}$} & C3 Evacuation action completed & $\begin{array}{l}\text { O6 Establish warning } \\
\text { zone }\end{array}$ & $\begin{array}{l}\text { MO4 Government organization: local } \\
\text { police station } \\
\text { MM1 Special facilities: warning tape }\end{array}$ \\
\hline
\end{tabular}




\subsection{Phase-IV: Petri Net Model}

Based on the transformation rules, from static model into dynamic model as suggested by Santarek and Buseif [21], the PN model was constructed for A32's five activities (A321, A322, A323, A324, and A325) built in the IDEF0 model at the previous stage (Figure 8), as shown in Figure 13. Following the $\mathrm{Tr}_{1}$ and $\mathrm{Tr}_{2}$ transformation rules, the PN model generated the following places: P321, P322, P323, P324, P325, P32-C1, P32-C2, P32-C3, P32-O1-C, P32-O5-C and transitions: T321-1, T321-2, T322-1, T322-2, T323-1, T323-2, T324-1, T324-2, T325-1, and T325-2 described in Table 8. The transformation rule, $\operatorname{Tr}_{3}(1)$ and (2), was used for the mechanisms to produce places P32-MO1, P32-MO3, P32-MO4, and P32-ME2 (Table 8). The PN model for "Monitor any possible disaster locations" (A32) consisted of 14 places and 10 transitions (Table 8).

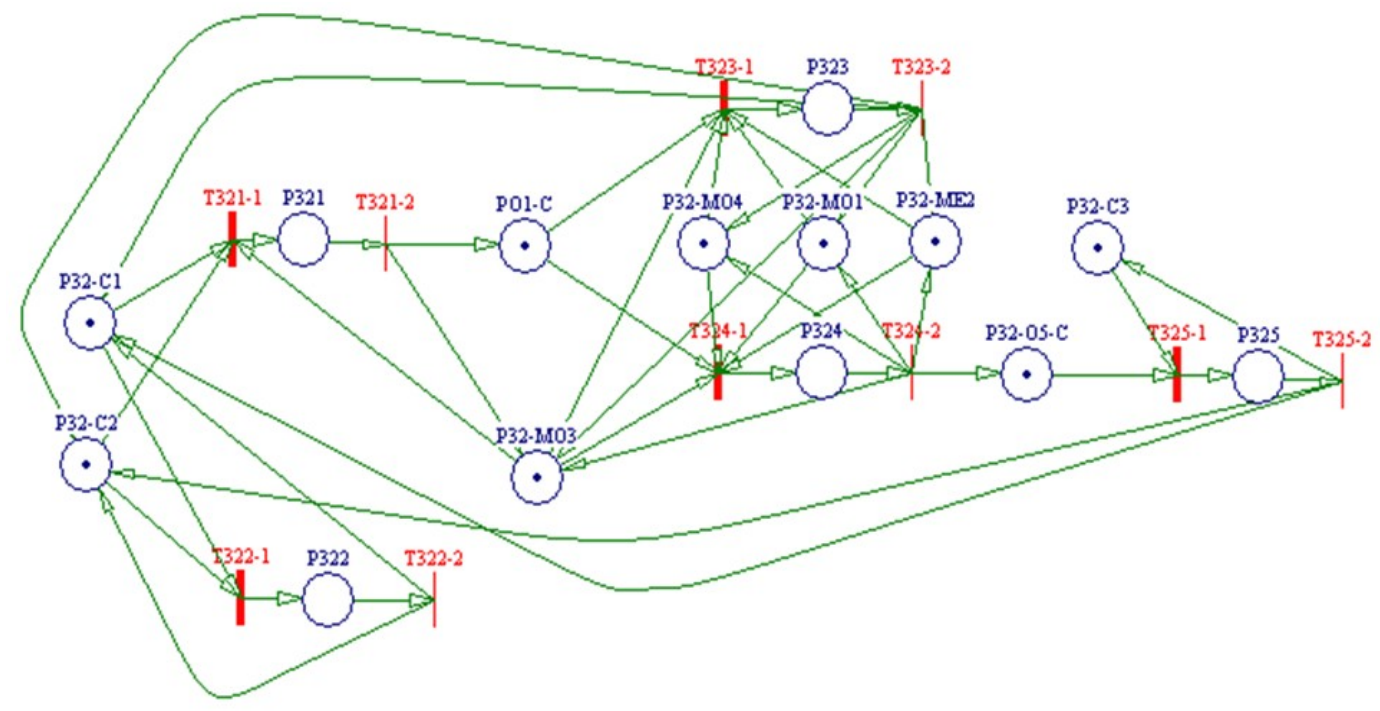

Figure 13. The Petri net (PN) model of the "Monitor any possible disaster locations" (A32).

Table 8. The notation of place and transition for "Monitor any possible disaster location" (A32).

\begin{tabular}{|c|c|c|c|c|c|}
\hline Place & Name & IDEF0 & Transition & Name & IDEF0 \\
\hline P1 & P321 & A321 Observe wild stream & $\mathrm{T} 1$ & T321-1 & A321 Start “Observe wild stream" \\
\hline $\mathrm{P} 2$ & P322 & A322 Patrol community & $\mathrm{T} 2$ & T321-2 & A321 End "Observe wild stream" \\
\hline P3 & P323 & A323 Announce second level situation & $\mathrm{T} 3$ & T322-1 & A322 Start "Patrol community" \\
\hline P4 & P324 & A324 Announce first level situation & $\mathrm{T} 4$ & T322-2 & A322 End "Patrol community" \\
\hline P5 & P325 & P325 Establish guard & T5 & T323-1 & $\begin{array}{l}\text { A323 Start "Announce second level } \\
\text { situation" }\end{array}$ \\
\hline P6 & P32-C1 & C1 Weather information & T6 & T323-2 & $\begin{array}{l}\text { A323 End "Announce second level } \\
\text { situation" }\end{array}$ \\
\hline P7 & P32-C2 & $\begin{array}{l}\text { C2 Community disaster protection } \\
\text { plan }\end{array}$ & $\mathrm{T} 7$ & T324-1 & $\begin{array}{l}\text { A324 Start "Announce first level } \\
\text { situation" }\end{array}$ \\
\hline P8 & P32-O1-C & $\begin{array}{l}\text { O1-C Hourly rainfall reaching } 200 \\
\text { mm (yellow alert) }\end{array}$ & $\mathrm{T} 8$ & T324-2 & $\begin{array}{l}\text { A324 End "Announce first level } \\
\text { situation" }\end{array}$ \\
\hline P9 & P32-O5-C & O5-C Compulsory evacuation & T9 & T325-1 & A325 Start "Establish guard" \\
\hline P10 & P32-C3 & C3 Evacuation action completed & $\mathrm{T} 10$ & T325-2 & A325 End "Establish guard" \\
\hline P11 & P32-MO1 & $\begin{array}{l}\text { MO1 Civil defense organization: } \\
\text { monitor team }\end{array}$ & & & \\
\hline P12 & P32-MO3 & $\begin{array}{l}\text { MO3 Civil defense organization: } \\
\text { command team and evacuation team }\end{array}$ & & & \\
\hline P13 & P32-MO4 & $\begin{array}{l}\text { MO4 Government organization: fire } \\
\text { brigade }\end{array}$ & & & \\
\hline P14 & P32-ME2 & $\begin{array}{l}\text { ME2 Communication facilities: } \\
\text { intercom, cellular phone }\end{array}$ & & & \\
\hline
\end{tabular}


After constructing the PN model, a DaNAMiCS software package was used to verify the behavioral properties of the developed Petri net model. The incidence matrix (D), P-invariants, and T-invariants are shown in Figure 14. The nonzero nonnegative integer entries in a P-invariant, such as $[1,1,1,1,1,1,1,1,0,0,0,0,0],[0,0,0,0,1,0,0,0,1,0,0,0,0],[0,0,1,1,0,0,0,0,0,1,0,0,0],[1,0,1,1,0,0,0,0,0,0,1,0,0]$, $[0,0,1,1,0,0,0,0,0,0,0,1,0],[0,0,1,1,0,0,0,0,0,0,0,0,1]$, revealed that the weights associated with the corresponding place as such that the weighted sum of tokens on these places was constant for all marking reachable from an initial marking. Similarly, for the purpose of avoiding deadlock, the nonzero nonnegative integer entries in a T-invariant, such as $[0,0,1,1,0,0,0,0,0,0],[1,1,0,0,1,1,0,0,0,0]$, $[1,1,0,0,0,0,1,1,1,1]$, represented not only the firing counts of the corresponding transitions that belonged to a firing sequence transforming a marking $\mathrm{m} 0$ back to $\mathrm{m} 0$, but also the number of times these transitions appeared in this sequence.

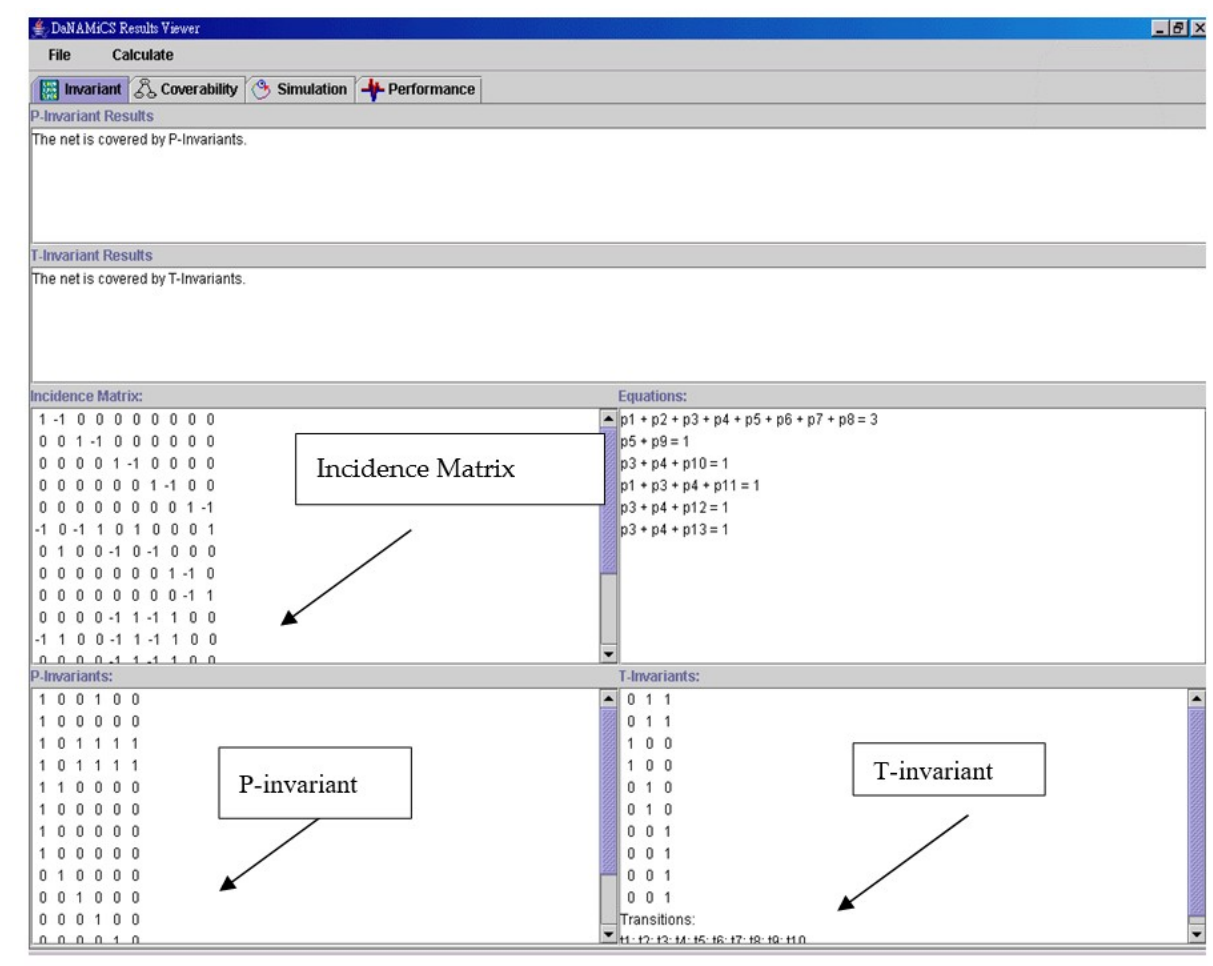

Figure 14. The places (P)-invariant and transition(T)-invariant values of A32.

\subsection{Phase-IV: Petri Net Mark Language (PNML)}

At the symbol level model (the bottom layer in Figure 1), in order to interweave understandable human symbols with a machine-readable format effectively, PNML was adopted as a starting point for a standard interchange format for Petri nets. The XML-based interchange format for the A32 Petri net model is shown in Figure 15. The relationships between the places and transitions and attributes of transitions are noted in this figure. 


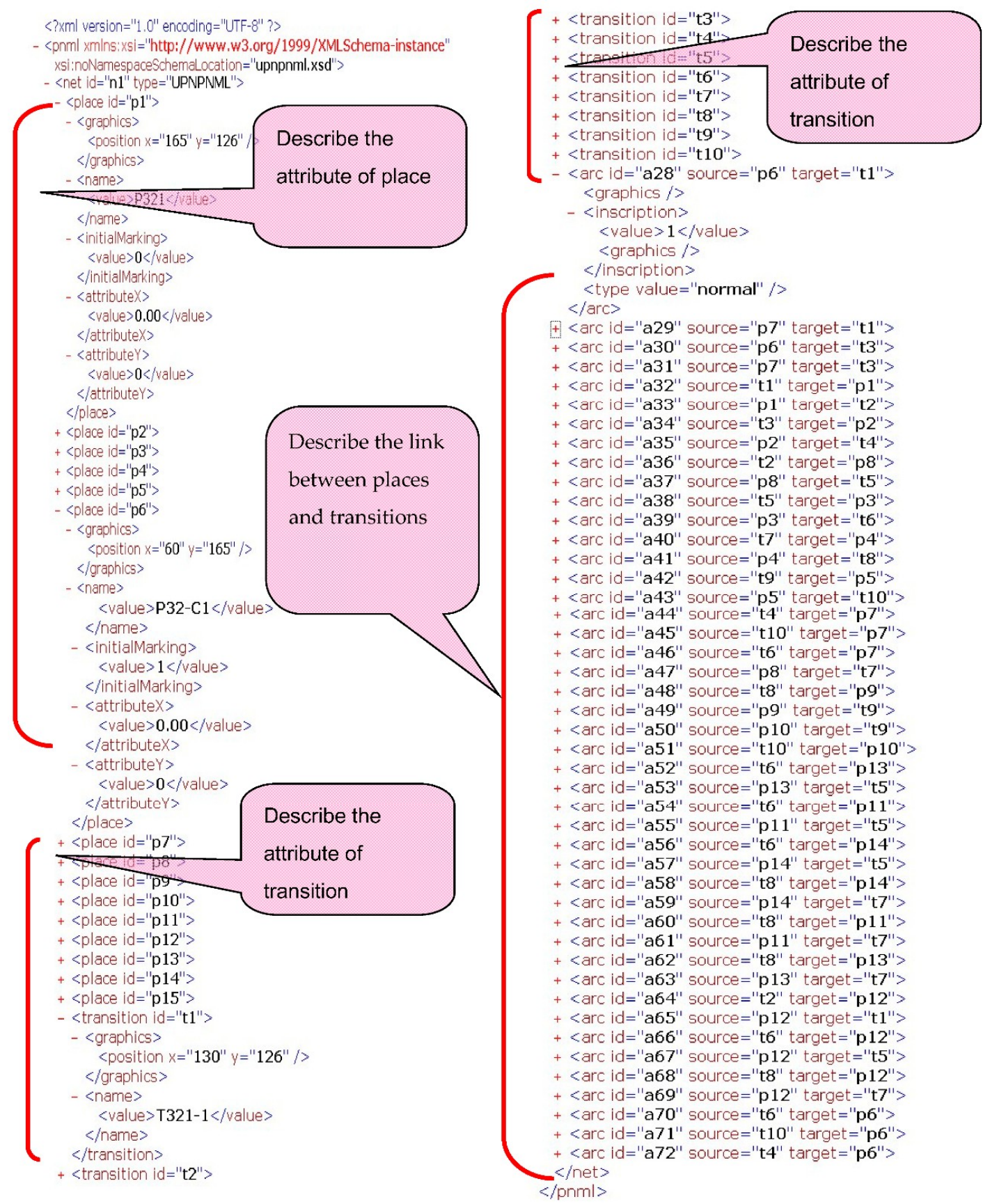

Figure 15. The XML-based interchange format for the Petri net model.

\section{Conclusions and Future Work}

Following the advent of Web service technology associated with the continuing rapid growth in knowledge management, problem-solving knowledge has increasingly grown dependent on the Internet, particularly in carrying out ICS operations. To bridge the gap in understanding and facilitate communications between computers and human beings, we presented the TTIPP framework and its related methodologies. The framework we developed consisted of three layers, including lexical, conceptual, and symbolic, and five phases: task analysis, task ontology, IDEF0 model, Petri net model, and PNML. The IDEF0 model was used to capture the requirements corresponding to the system specification at the stage of functional analysis. Subsequently, at the stage of behavior analysis, the Petri net model was constructed according to the IDEF0 model. Finally, at the implementation stage, the model could be realized by using PNML. 
The TTIPP methodology is general and can be used to solve any linguistic problem. It provides a sound ontological foundation for different problem-solving approaches and can be used to support a great variety of task modeling, independent of the target shell or computational method. The TTIPP model overcomes the drawbacks of IDEF0 in terms of its static nature and Petri net with no hierarchy for concepts. Moreover, it not only enables better access to information and promotes shared understanding of real-world problem-solving knowledge for humans in an explicit and reusable manner, but also facilitates comprehension of information and better processing by computers.

Protecting people from natural calamities and maintaining the quality of the natural environment are complex problems. It requires the development of an effective incident command system which requires collaboration and participation among government agencies, academic institutes, private industries, non-governmental organizations, and local communities. As an example, the TTIPP model was applied to the task of emergency response for debris-flow during a typhoon as a part of an ICS.

Within the field of knowledge management, future research should focus on developing reusable and sharable real-world problem-solving knowledge models. We plan to use the TTIPP methodology as a major building block for developing generic semantic web problem-solvers.

Author Contributions: K.F. developed the concept of the TTIPP methodology, analyzed the task, developed the task ontology, built the IDEFO and Petri Net model, transferred the PNML. S.L. interviewed the stakeholders and transferred verbatim. K.F. wrote the paper.

Funding: This research was supported in part by the following National Science Council (NSC) grants: NSC 93-2625-Z-224-002.

Conflicts of Interest: The authors declare no conflict of interest.

\section{References}

1. Latest Earthquakes in the World. Available online: https://www.emsc-csem.org/Earthquake/world/ (accessed on 1 April 2019).

2. Dutta, A. Integrating ai and optimization for decision support: A survey. Decis. Support Syst. 1996, 18, 217-226. [CrossRef]

3. Geamsakul, W.; Yoshida, T.; Ohara, K.; Motoda, H.; Yokoi, H.; Takabayashi, K. Constructing a decision tree for graph-structured data and its applications. Fundam. Inf. 2005, 66, 131-160.

4. Ghenniwa, H.; Huhns, M.; Shen, W. Emarketplaces for enterprise and cross enterprise integration. Data Knowl. Eng. 2005, 52, 33-59. [CrossRef]

5. Nora, M.; El-Gohary, A.; El-Diraby, T. Dynamic knowledge-based process integration portal for collaborative construction. J. Constr. Eng. Manag. 2010, 136, 316-328.

6. Schreiber, G.H.; Akkermans, H.; Anjewierden, A.; de Hoog, R. Knowledge Engineering and Management: The Common KADS Methodology; MIT Press: Boston, MA, USA, 2000.

7. Kendal, S.; Creen, M. An Introduction to Knowledge Engineering; Springer: London, UK, 2007.

8. Nonaka, I. The knowledge-creating company. Harv. Bus. Rev. 1991, 69, 96-104.

9. Alonderienne, R.; Pundziene, A.; Krisciunas, K. Tacit knowledge acquisition and transfer in the process of informal learning. Probl. Perspect. Manag. 2006, 4, 134-145.

10. Fuster, J.M. Hayek in today's cognitive neuroscience. In Advance in Austrian Economic; Emerald Publishing Limited: Bingley, UK, January 2011.

11. Erkut, B. Product innovation and market shaping: Bridging the gap with cognitive evolutionary economics. IJM 2016, 4, 3-24.

12. Kaya, T.; Erkut, B. Tacit knowledge capacity: A comparison of university lecturers in Germany and North Cyprus. Electr. J. Knowl. Manag. 2018, 16, 131-142.

13. Polanyi, M. The Tacit Dimension; Garden City: New York, NY, USA, 1966.

14. Rahe, M. Subjectivity and cognition in knowledge management. J. Knowl. Manag. 2009, 13, 102-117. [CrossRef]

15. Nonaka, I.; Takeuchi, H. The Knowledge Creating Company; Oxford University Press: Oxford, UK, 1995.

16. Weiss, S.M.; Indurkhya, N.; Zhang, T. Fundamentals of Predictive Text Mining; Springer: Berlin, Germany, 2015. 
17. Fronzetti Colladon, A.; Gloor, P.A. Measuring the impact of spammers on email and twitter networks. Int. J. Inf. Manag. 2018. [CrossRef]

18. Aloini, D.; Benevento, E.; Stefanini, A.; Zerbino, P. Process fragmentation and port performance: Merging SNA and text mining. Int. J. Inf. Manag. 2019, in press. [CrossRef]

19. Labuschagnea, C.; Brenta, A.C.; Ron, P.G.; Van Ercka, P.G. Assessing the sustainability performances of industries. J. Clean. Prod. 2005, 13, 373-385. [CrossRef]

20. Miemczyk, J.; Johnsen, T.E.; Macquet, M. Sustainable purchasing and supply management: A structured literature review of definitions and measures at the dyad, chain and network levels. Supply Chain Manag. 2012, 17, 478-496. [CrossRef]

21. Santarek, K.; Buseif, I.M. Modelling and design of flexible manufacturing systems using SADT and Petri nets tools. J. Mater. Process. Technol. 1998, 76, 212-218. [CrossRef]

22. Gold, A.H.; Malhotra, A.; Segars, A.H. Knowledge management: An organizational capabilities perspective. J. Manag. Inf. Syst. 2001, 18, 185-214. [CrossRef]

23. Adeli, H. Knowledge Engineering_Volume One—Fundamentals; McGraw-Hill Book Company: New York, NY, USA, 1990.

24. Adeli, H. Knowledge Engineering_Volume Two-Applications; McGraw-Hill Book Company: New York, NY, USA, 1990.

25. Moreno, V., Jr.; Cavazotteb, F. Using information systems to leverage knowledge management processes: The role of work context, job characteristics and task-technology Fit. Proc. Comput. Sci. 2015, 55, 360-369. [CrossRef]

26. Yang, W.; McKinnon, M.C.; Turner, W.R. Quantifying human well-being for sustainability research and policy. Ecosyst. Health Sustain. 2015, 1, 1-13. [CrossRef]

27. Corcho, O.; Fernandez-Lopez, M.; Gomez-Perez, A.; Lopez-Cima, A. Building Legal Ontologies with METHONTOLOGY and WebODE. Lect. Notes Comput. Sci. 2005, 3369, 142-157. [CrossRef]

28. Kotis, K.; Vouros, G. Human-centered ontology engineering: The HCOME methodology. Knowl. Inf. Syst. 2006, 10, 109-131. [CrossRef]

29. Villazon-Terrazas, B.; Ramirez, J.; Suarez-Figueroa, M.C.; Gomez-Perez, A. A network of ontology networks for building e-employment advanced systems. Expert Syst. Appl. 2011, 38, 13612-13624. [CrossRef]

30. Pinto, H.S.; Tempich, C.; Staab, S. Ontology engineering and evolution in a distributed world using DILIGENT. In Handbook on Ontologies_International Handbooks on Information Systems, 2nd ed.; Staab, S., Studer, R., Eds.; Springer: Berlin, Germany, 2009; pp. 153-176.

31. Saa, R.; Garcia, A.; Gomez, C.; Carretero, J.; Garcia-Carballeira, F. An ontology-driven decision support system for high-performance and cost-optimized design of complex railway portal frames. Expert Syst. Appl. 2012, 39, 8784-8792. [CrossRef]

32. Ziemba, P.; Watróbski, J.; Jankowski, J.; Wolski, W. Construction and restructuring of the knowledge repository of website evaluation methods. In Information Technology for Management-Lecture Notes in Business Information Processing; Ziemba, E., Ed.; Springer Nature: Basel, Switzerland, 2016; Volume 243, pp. 29-52.

33. Elias, M.; Lohmann, S.; Auer, S. Ontology-based representation for accessible opencourseware systems. Information 2018, 9, 302. [CrossRef]

34. Meng, X.; Xu, C.; Liu, X.; Bai, J.; Zheng, W.; Chang, H.; Chen, Z. An ontology-underpinned emergency response system for water pollution accidents. Sustainability 2018, 10, 546. [CrossRef]

35. Konys, A. An ontology-based knowledge modelling for a sustainability assessment domain. Sustainability 2018, 10, 300. [CrossRef]

36. Gloor, P.A.; Fronzetti Colladon, A.; Grippa, F.; Giacomelli, G. Forecasting managerial turnover through e-mail based social network analysis. Comput. Hum. Behav. 2017, 71,343-352. [CrossRef]

37. Antonacci, G.; Fronzetti Colladon, A.; Stefanini, A.; Gloor, P. It is rotating leaders who build the swarm: Social network determinants of growth for healthcare virtual communities of practice. J.Knowl. Manag. 2017, 21, 1218-1239. [CrossRef]

38. Barker, R. Management of knowledge creation and sharing to create virtual knowledge-sharing communities: A tracking study. J. Knowl. Manag. 2015, 19, 334-350. [CrossRef]

39. Noy, N.F.; Musen, M.A. Ontology versioning in an ontology management framework. IEEE Intell. Syst. 2004, 19, 6-13. [CrossRef] 
40. Therani, M. Ontology development for designing and managing dynamic business process networks. IEEE Trans. Ind. Inf. 2007, 3, 173-185. [CrossRef]

41. Mizoguchi, R.; Tijerino, Y.; Ikeda, M. Task analysis interview based on task ontology. Expert Syst. Appl. 1995, 9, 15-25. [CrossRef]

42. Mohammad, A.; Zakaria, N.; Hidayati, N.; Darshana, S. Ontology-based knowledge management for enterprise systems. Int. J. Enterp. Inf. Syst. 2011, 7, 64-90.

43. Gruber, T.R.A. A translation approach to portable ontology specification. Knowl. Acquis. 1993, 5, $199-221$. [CrossRef]

44. Musen, M.A. The Protégé project: A look back and a look forward. AI Matters 2015, 1, 4-12. [CrossRef] [PubMed]

45. David, R.; Alla, H. Petri Nets for modeling of dynamics systems-A survey. Automatica 1994, 30, $175-202$. [CrossRef]

46. Gomez-Perez, A.; Fernandez-Lopez, M.; Corcho, O. Ontology Engineering; Springer: Berlin/Heidelberg, Germany, 2004.

47. Shih, D.H.; Chiang, H.S.; Lin, B. A generalized associative Petri Net for reasoning. IEEE Trans. Knowl. Data Eng. 2007, 19, 1241-1251. [CrossRef]

48. Bialas, A. Computer-aided sensor development focused on security issues. Sensors 2016, 16, 759. [CrossRef] [PubMed]

49. Park, H. Task model and task ontology based on mobile users' generic activities for task-oriented tourist information service. Int. J. Smart Home 2013, 7, 33-44.

50. Van Heijst, G.; Schreiber, A.T.; Wielinga, B.J. Using explicit ontologies in KBS development. Int. J. Hum. Comput. Stud. 1997, 46, 183-292. [CrossRef]

51. Guarino, N. Formal Ontology and Information System. 1998. Available online: http://www.loa-cnr.it/Papers/ FOIS98.pdf (accessed on 11 June 2015).

52. Lassila, A.; McGuinness, D. The Role of Frame-Based Representation on the Semantic Web (Ksl-01-02); Knowledge System Laboratory, Stanford University: Stanford, CA, USA, 2001.

53. Benjamins, V.R.; Gomez-Perez, A. Knowledge-system technology: Ontologies and problem-solving. 2004. Available online: http://hcs.science.uva.nl/usr/richard/pdf/kais.pdf (accessed on 6 October 2004).

54. Chandrasekaran, B.; Benjamins, V.R. What are ontologies, and why do we need them. IEEE Intell. Syst. 1999, 14, 20-26. [CrossRef]

55. Newell, A. The knowledge-level. Artif. Intell. 1982, 18, 87-127. [CrossRef]

56. Mizoguchi, R.; Sunagawa, E.; Kozaki, K.; Kitamura, Y. A model of roles within an ontology development tool: Hozo. J. Appl. Ontol. 2007, 2, 159-179.

57. Ikeda, M.; Seta, K.; Kakusho, O.; Mizoguchi, R. Task ontology: Ontology for building conceptual problem solving models. In Proceedings of the ECAI98 Workshop on Applications of Ontologies and Problem-Solving Model, Osaka, Japan, 23-28 August 1998; pp. 126-133.

58. Rajpathak, G.D.; Motta, E.; Zdráhal, Z.; Roy, R. A generic library of problem solving methods for scheduling applications. IEEE Trans. Knowl. Data Eng. 2006, 18, 815-828. [CrossRef]

59. Tho, Q.T.; Hui, S.C.; Fong, A.C.M.; Cao, T.H. Automatic fuzzy ontology generation for semantic Web. IEEE Trans. Knowl. Data Eng. 2006, 18, 842-856. [CrossRef]

60. Berner-Lee, T. Weaving the Web: The Original Design and Ultimate Destiny of the World Wide Web by its Inventor; HarperCollins Publishers: New York, NY, USA, 1999.

61. Corby, O.; Dieng-Kuntz, R.; Gandon, F.; Faron-Zucker, C. Searching the semantic web: Approximate query processing based on ontologies. IEEE Intell. Syst. 2006, 21, 20-27. [CrossRef]

62. Colguhoun, G.J.; Baines, R.W.; Crossley, R. A composite behavior modeling approach for manufacturing enterprise. Int. J. Comput. Integr. Manuf. 1996, 9, 463-475. [CrossRef]

63. Pan, J.Z. A flexible ontology reasoning architecture for the semantic web. IEEE Trans. Knowl. Data Eng. 2007, 19, 246-260. [CrossRef]

64. Farida, B.-D.; Catherine, C.; Malik, S.-M.; Pierre-Jean, C. Ontology based teaching domain knowledge management for E-Learning by doing systems. Electr. J. Knowl. Manag. 2015, 13, 156-171.

65. Ross, D.T. Application and extensions of SADT. Computer IEEE 1985, 18, 25-34. [CrossRef]

66. Feldmann, C.G. The Practical Guide to Business Process Reengineering Using IDEF0; Dorset House Publishing: New York, NY, USA, 1998. 
67. Lee, J.S.; Hsu, P.L. An IDEF0/Petri Net approach to the system integration in semiconductor manufacturing systems. IEEE Int. Conf. Syst. Man Cybern. 2003, 5, 4910-4915.

68. Zhou, M.C.; Jeng, M.D. Modeling, analysis, simulation, scheduling, and control of semiconductor manufacturing systems: A Petri Net approach. IEEE Trans. Semicond. Manuf. 1998, 11, 333-357. [CrossRef]

69. Cassandras, C.G.; Lafortune, S. Introduction to Discrete Systems; Kluwer: Boston, MA, USA, 1999.

70. Murata, T. Petri Nets: Properties, analysis and application. Proc. IEEE 1989, 77, 541-580. [CrossRef]

71. Billington, J.; Christensen, S.; van Hee, K.; Kinder, E.; Kummer, O.; Petrucci, L. The Petri Net Markup Language: Concepts, Technology, and Tools. 2004. Available online: http://www.informtik.hu-berlin.de/top/PNX (accessed on 25 October 2008).

(C) 2019 by the authors. Licensee MDPI, Basel, Switzerland. This article is an open access article distributed under the terms and conditions of the Creative Commons Attribution (CC BY) license (http://creativecommons.org/licenses/by/4.0/). 